Colloids Surfaces A, 519, 87-97 (2017); http://dx.doi.org/10.1016/j.colsurfa.2016.06.039

\title{
Sulfonated methyl esters, linear alkylbenzene sulfonates and their mixed solutions: micellization and effect of $\mathrm{Ca}^{2+}$ ions
}

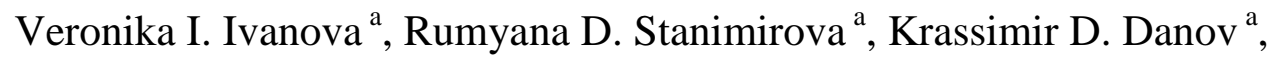 \\ Peter A. Kralchevsky ${ }^{\text {a, }}$, Jordan T. Petkov ${ }^{\text {b }}$ \\ ${ }^{a}$ Department of Chemical \& Pharmaceutical Engineering, Faculty of Chemistry \& Pharmacy, Sofia \\ University, 1164 Sofia, Bulgaria. \\ ${ }^{b}$ KL-Kepong Oleomas SDN BHD, Menara KLK, Jalan PJU 7/6, Mutiara Damansara, 47810 Petaling \\ Jaya, Selangor Dalur Ehsan, Malaysia
}

\begin{abstract}
Here, we compare the properties of sulfonated methyl esters of fatty acids (SME) and linear alkylbenzene sulfonate (LAS) with respect to the effect of calcium ions on their surface tension and the effect of their mixing on the critical micelle concentration (CMC). The theoretical interpretation of surface tension isotherms obtained in the presence of $\mathrm{NaCl}$ and $\mathrm{CaCl}_{2}$ allowed us to determine the parameters that characterize the surfactant adsorption layers and counterion binding. The excluded area per molecule in the adsorption layer is the same for SME and LAS, and is determined by the cross-sectional area of the sulfonate headgroup. The binding energy of $\mathrm{Na}^{+}$ions to the headgroups of SME and LAS is also the same. However, the binding energy of the $\mathrm{Ca}^{2+}$ ion to the headgroup of LAS is considerably greater than that of SME in agreement with the circumstance that LAS is precipitated by hard water. In contrast, the binding energy of the $\mathrm{Ca}^{2+}$ ion to the headgroup of SME is lower even than that of $\mathrm{Na}^{+}$, in accord with the reputation of SME as one of the most hard-water tolerant surfactants. The dependencies of the CMC on the composition of binary mixed surfactant solutions reveal that C14-SME and C16-SME exhibit ideal mixing; C14-SME and LAS slightly synergistic mixing, whereas C16-SME and LAS - antagonistic mixing due to hydrocarbon-chain mismatch. The micellization in mixed solutions of SME and cocamidopropyl betaine has been also investigated. The results in the present study allow prediction of the surface tension of solutions of SME and LAS in the presence of $\mathrm{Na}^{+}$and $\mathrm{Ca}^{2+}$ ions at various concentrations; contribute for a better understanding of the different tolerance of SME and LAS to hard water, and quantify the effect of their mixing on the CMC.
\end{abstract}

Keywords:

Sulfonated methyl esters; Linear alkylbenzene sulfonates; Surfactant tolerance to hard water; Energy of counterion binding; Critical micelle concentration; Synergistic vs. antagonistic mixing.

\footnotetext{
* Corresponding author. Tel.: +359 28161262.

Email address: pk@lcpe.uni-sofia.bg (P.A. Kralchevsky)
} 


\section{Introduction}

The sulfonated methyl esters (SME), known also as $\alpha$-sulfo fatty acid methyl ester sulfonates ( $\alpha$-MES), sodium salts (Fig. 1a), exhibit a series of useful properties, which make them attractive for various applications [1-5]: excellent biodegradation; excellent water hardness stability that allows them to be formulated in hard-water regions; very good ability to dissolve calcium-soap scum; excellent skin compatibility that makes them potentially very good for hand dishwashing formulations and body care products; very good wetting power; good detergent power, and very low viscosity of their aqueous solutions (at concentrations comparable with those of other surfactants), which makes them easy to handle and pump. Sodium methyl ester sulfonates with random positioning of the $\mathrm{SO}_{3}$ group in the alkyl chain, known as $\Phi$-MES, have been synthesized to increase the water solubility of this class of surfactants [1-3]. SMEs are used in cleaning formulations, such as phosphate-free detergent powders [6,7] and in viscous formulations, in mixture with nanoparticles [8]. The sulfonated methyl esters are considered as an environmentally friendly and calcium tolerant alternative of the linear alkylbenzene sulfonates (LAS) [9]; see Fig. 1b. The production of SME has been growing during the last decade and currently it stands at more than ten percent of the LAS production.

(a)

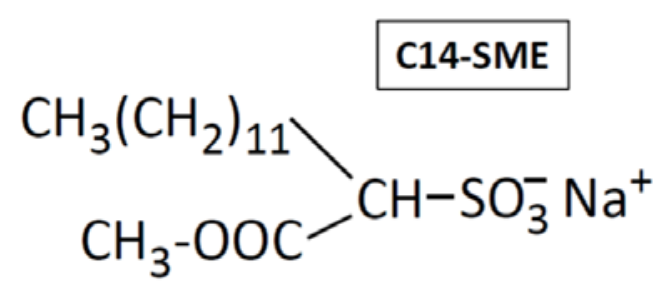

(b)

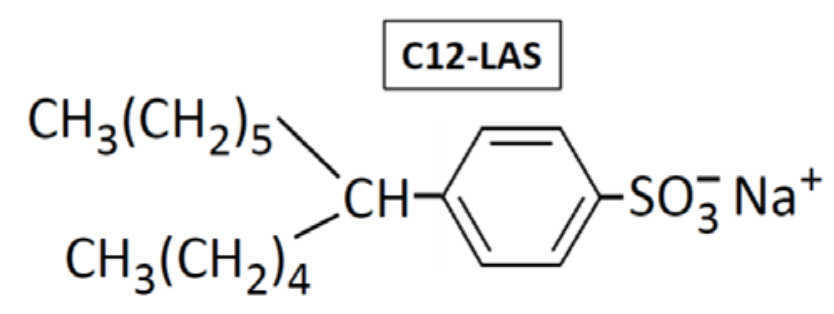

Fig. 1. Comparison of the structural formulas of (a) C14-SME and (b) C12-LAS; the most abundant positional isomer of para-dodecyl benzene sulfonate in the used batch is shown.

The adsorption of LAS at oil/water interfaces in the presence of $\mathrm{Ca}^{2+}$ ions was recently investigated [10]. LAS is surfactant with a relatively low tolerance to hard water. The 
solubility product of the calcium salt of LAS was determined by Matheson et al. [11] for different chainlengths. According to Satzuki et al. [12], LAS is very sensitive to calcium concentration because of the production of liquid crystalline calcium salt, which is insoluble. On the other hand, the reason why SME is reasonably hardness tolerant is because there is some shield effect of the $\mathrm{CO}_{2} \mathrm{ME}$ group, which results in a weaker interaction with calcium ions [3].

In our previous study [13], we investigated the properties of aqueous SME solutions, including their surface tension isotherms, critical micelle concentration (CMC) and its dependence on the concentration of added $\mathrm{NaCl}$. Using SME as an example, we demonstrated the application of a new and powerful method for determining the physicochemical parameters of the pure ionic surfactant by theoretical data analysis (“computer purification”) if the used surfactant sample contains nonionic admixtures, which are present as a rule. This method involves fits of the experimental data for surface tension and conductivity by a physicochemical model based on a system of mass-balance, chemical-equilibrium and electric-double-layer equations, which allows one to determine the adsorption and micellization parameters of the pure surfactants and to quantify the effect of the nonionic admixture. One can further predict the interfacial and micellization properties of the surfactant solutions, such as surface tension, adsorption, degree of counterion binding, surface electric potential, etc. at every surfactant, salt and co-surfactant concentrations [13].

In the present article, we extend our study by comparing the properties of SME and LAS at the air/water interface with respect to the effect of calcium ions on their surface tension and the effect of their mixing on the critical micelle concentration. Insofar as SME and LAS are surfactants, respectively, of high and low water-hardness stability, it is interesting to determine and compare the Stern constants that characterize the binding of $\mathrm{Ca}^{2+}$ ions to the headgroups of these surfactants. For this goal, surface tension isotherms of SME and LAS were measured in the presence of $\mathrm{CaCl}_{2}$, and compared with similar isotherms in the presence of $\mathrm{NaCl}$ (Section 3). Because the commercially available samples of both SME and LAS always contain admixtures of unsulfonated surfactant, which affects their surfacetension isotherms, the method of "computer purification" [13] was applied to quantify the effect of the nonionic admixture and to determine all adsorption constants of the anionic SME and LAS, including the binding energies of $\mathrm{Na}^{+}$and $\mathrm{Ca}^{2+}$ counterions to their headgroups. The surfactant adsorptions, surface electric potentials and occupancies of the Stern layer upon competitive adsorption of these two counterions are estimated as functions 
of the surfactant concentration (Section 4). Finally, in Section 5 we present experimental data for the CMC of mixed solutions of SME and LAS, to investigate whether these surfactants exhibit ideal, synergistic or antagonistic mixing in the micellar pseudophase. Because of the frequent use of cocamidopropyl betaine (CAPB) in personal-care detergency, the micellization in mixed solutions of SME and CAPB has been also investigated (Section 5).

\section{Materials and methods}

Sulfonated methyl esters (SME) of the myristic and palmitic acids (C14 and C16), produced by the Malaysian Palm Oil Board (MPOB) and KLK OLEO were used in our experiments. For brevity, the notation $\mathrm{Cn}$-SME will be used, where $n$ stands for the number of carbon atoms in the fatty-acid chain (in our case, $n=14$ and 16). C14-SME of molecular weight $M_{\mathrm{w}}=344 \mathrm{~g} / \mathrm{mol}$ was received as a dry powder. C16-SME, $M_{\mathrm{w}}=372 \mathrm{~g} / \mathrm{mol}$, was supplied as a dry dispersion composed of small flakes. These samples were used in our experiments without any additional purification.

The used SME samples have been characterized by liquid chromatography-mass spectrometry (LC/MS) analysis. The purity of C14- and C16-SME is, respectively, 97.9 and 96.0 \%. The structural formula of C14-SME is shown in Fig. 1a. The admixtures represent small amounts of Cn-SME with the neighboring even values of $n$. Traces of unsulfonated methyl esters ( $\mathrm{Cn}-\mathrm{ME})$ in the used samples are also present. They are inaccessible to the conventional analytical methods, but have been determined by a combination of surface tension and conductivity measurements, as demonstrated in our previous study [13]. Karl Fischer analysis was carried out to determine the amounts of water in the used SME samples and to work with the correct surfactant concentrations.

In comparative experiments, linear alkylbenzene sulfonate (LAS), sodium salt (technical grade, $92 \%, M_{\mathrm{w}}=348.5 \mathrm{~g} / \mathrm{mol}, \mathrm{CMC}=1.7 \mathrm{mM}$; donated by Unilever R\&D) was used. By HPLC analysis, following a procedure developed by Ma et al. [14] it was established that the LAS sample is a mixture of alkyl chain homologues with chain length from C10 to C13, where C12 is the predominant component. Moreover, each homologue represents a mixture of headgroup positional isomers. They have a molecular structure where the benzene sulfonate headgroup is attached at different positions along the alkyl chain [14]. For our sample, predominant were the positional isomers, for which the headgroup is attached near 
the middle of the alkyl chain (Fig. 1b), whereas isomers with headgroup attached at the end of the alkyl chain were not detected.

In some experiments, we used also the zwitterionic surfactant cocamidopropyl betaine (CAPB), product of Goldschmidt GmbH; commercial name Tego® Betain F50; molecular mass $356 \mathrm{~g} / \mathrm{mol}$, which finds a wide application in personal-care detergency. The critical micellization concentration of CAPB is $\mathrm{CMC}_{S}=9 \times 10^{-5} \mathrm{M}$ determined by surface tension measurements at $25^{\circ} \mathrm{C}$.

Sodium chloride, $\mathrm{NaCl}$, calcium chloride, $\mathrm{CaCl}_{2} \cdot 6 \mathrm{H} 2 \mathrm{O}$, and sodium hydroxide, $\mathrm{NaOH}$, all products of Sigma-Aldrich, Germany, were used as additives. The aqueous solutions were prepared with deionized water purified by Elix 3 water purification system (Millipore). All experiments were carried out at a temperature of $25^{\circ} \mathrm{C}$.

The equilibrium surface tension, $\sigma$, was measured by the du Noüy ring method using tensiometer K100 (Krüss GmbH, Germany) equipped with a platinum-iridium ring. The duration of each measurement was at least $30 \mathrm{~min}$ at the higher concentrations and ionic strengths, and $60 \mathrm{~min}$ at the lower concentrations. The electrical conductivity of aqueous surfactant solutions was measured with Hanna EC 215 conductivity meter.

\section{Experimental results for surface tension}

In Fig. 2, we compare experimental data for C14- and C16-SME, and LAS in the presence of $\mathrm{NaCl}$ and $\mathrm{CaCl}_{2} .10 \mathrm{mM} \mathrm{NaOH}$ was added to the SME solutions to suppress the effect of minor fatty-acid admixtures in the used SME samples. The symbols represent experimental results, whereas the solid lines are the best fits by the adsorption model (see Section 4). The data for SME $+\mathrm{NaCl}$ in Figs. 2a and b are from Ref. [13], whereas all other experimental data and theoretical curves are first reported in the present article.

As expected, the surface tension decreases with the rise of $\mathrm{NaCl}$ concentration, which is due to increasing counterion adsorption (binding) [15-20]. In our case, $\mathrm{Na}^{+}$counterions bind to the negatively charged sulfonate headgroups of the adsorbed surfactant molecules. As seen in Figs. 2a,b, the addition of $2.4 \mathrm{mM} \mathrm{CaCl}_{2}$, produces a greater lowering of surface tension than $20 \mathrm{mM} \mathrm{NaCl}$. This $\mathrm{CaCl}_{2}$ concentration corresponds to very hard water. (According to the classification of the US Geological Survey, very hard water is that with $\left[\mathrm{Ca}^{2+}\right]>1.81$ $\mathrm{mM})$. 
(a)

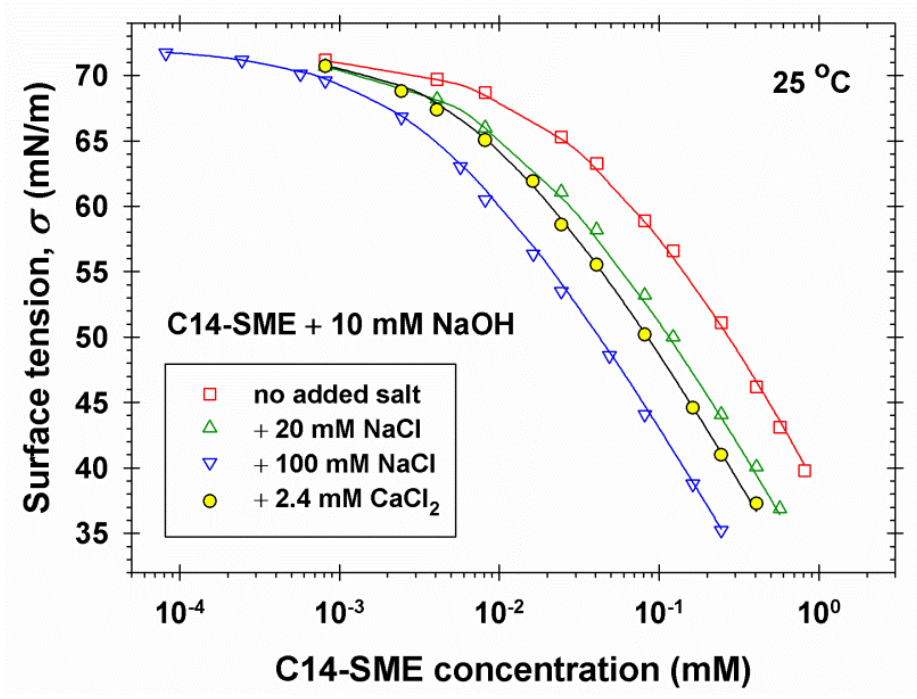

(b)
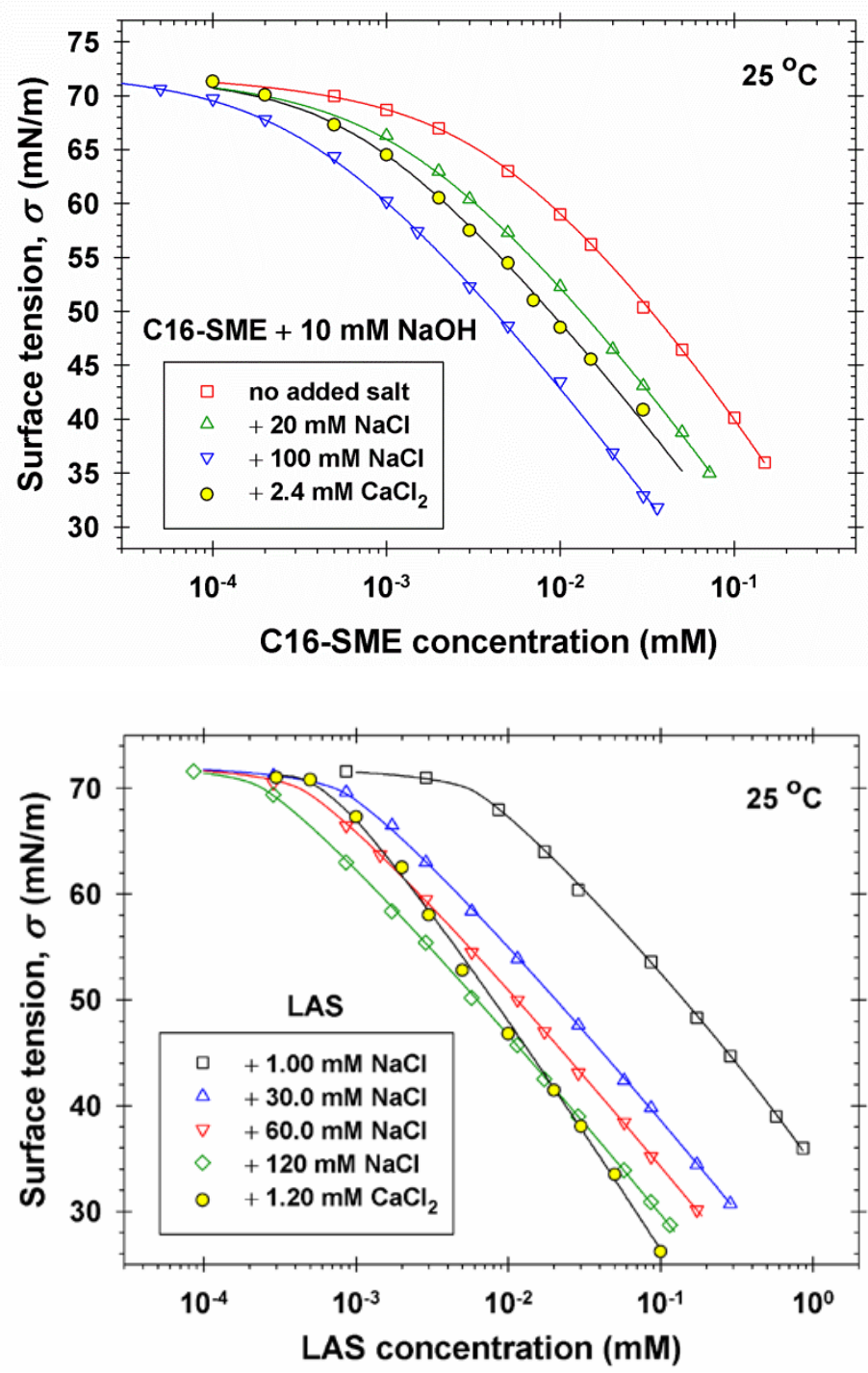

Fig. 2. Surface tension $\sigma$ vs. the surfactant concentration: data for (a) C14-SME; (b) C16SME and (c) LAS at different $\mathrm{NaCl}$ and $\mathrm{CaCl}_{2}$ concentrations denoted in the figure. The solid lines represent the best fits of the data with the theoretical model (see the text). 
In the case of LAS, a twice lower concentration of $\mathrm{CaCl}_{2}$ was used, $1.20 \mathrm{mM}$, to avoid precipitation. All experimental points in Fig. 2c correspond to clear solutions, without precipitate from $\mathrm{Ca}(\mathrm{LAS})_{2}$ crystallites. According to Matheson et al. [11], the solubility product of $\mathrm{Ca}(\mathrm{LAS})_{2}$ is $1.8 \times 10^{-11} \mathrm{M}^{3}$ for LAS with 11.4 average number of $\mathrm{C}$ atoms. The rightmost point for the curve with $\mathrm{CaCl}_{2}$ in Fig. 2c corresponds to $1.2 \times 10^{-11} \mathrm{M}^{3}$, which is slightly below the solubility product. The respective experimental point for $1.2 \mathrm{mM} \mathrm{CaCl}$ and $10^{-1} \mathrm{mM}$ LAS corresponds to a surface-tension value, which is lower than $\sigma$ for $120 \mathrm{mM}$ $\mathrm{NaCl}$ at the same LAS concentration. The fact that $\mathrm{CaCl}_{2}$ produces greater effect than $\mathrm{NaCl}$ at 100 times lower concentration indicates a considerably greater degree of $\mathrm{Ca}^{2+}$ binding to the LAS headgroups in the adsorption layer, in comparison with $\mathrm{Na}^{+}$. This effect is quantified and interpreted in the next section, in the framework of a theoretical adsorption model.

\section{Theoretical model and data interpretation}

There are two possible reasons for the greater degree of binding of the $\mathrm{Ca}^{2+}$ ions in comparison with the $\mathrm{Na}^{+}$ions:

(i) The binding energy of the $\mathrm{Ca}^{2+}$ ions to the surfactant headgroups is greater than that of the $\mathrm{Na}^{+}$ions.

(ii) The concentration of divalent $\mathrm{Ca}^{2+}$ ions in the vicinity of the negatively charged surfactant adsorption layer is higher than that of the monovalent $\mathrm{Na}^{+}$ions. This could lead to a greater degree of $\mathrm{Ca}^{2+}$ binding even if the binding energy of calcium is the same as (or smaller than) that of sodium.

Here, by theoretical analysis of the surface tension isotherms in Fig. 2 the binding energies of $\mathrm{Na}^{+}$and $\mathrm{Ca}^{2+}$ counterions to the headgroups of SME and LAS will be determined and compared. It will be demonstrated that the greater binding of the $\mathrm{Ca}^{2+}$ ions to the headgroups of SME is due to the second of the above two possible reasons, whereas in the case LAS - a combination of both of them takes place.

\subsection{Model for a mixture of ionic and nonionic surfactants}

As already mentioned, the used samples of SME and LAS (as well as most samples of ionic surfactants in practical applications) contain small nonionic admixtures that, however, strongly affect their surface-tension isotherms. In the case of Cn-SME, the main nonionic admixture is of unsulfonated methyl ester (Cn-ME) [13], whereas in the case of LAS - of 
unsulfonated linear alkyl benzene (LAB) [21]. Because of the different effect of added electrolyte on the adsorption of ionic surfactant and nonionic admixture, the simultaneous processing of several surface tension isotherms obtained at different concentrations of added electrolyte enables one to determine the adsorption parameters of the pure ionic surfactant, as well as the amount of nonionic admixture (“computer purification”) [13,20,21].

(a)

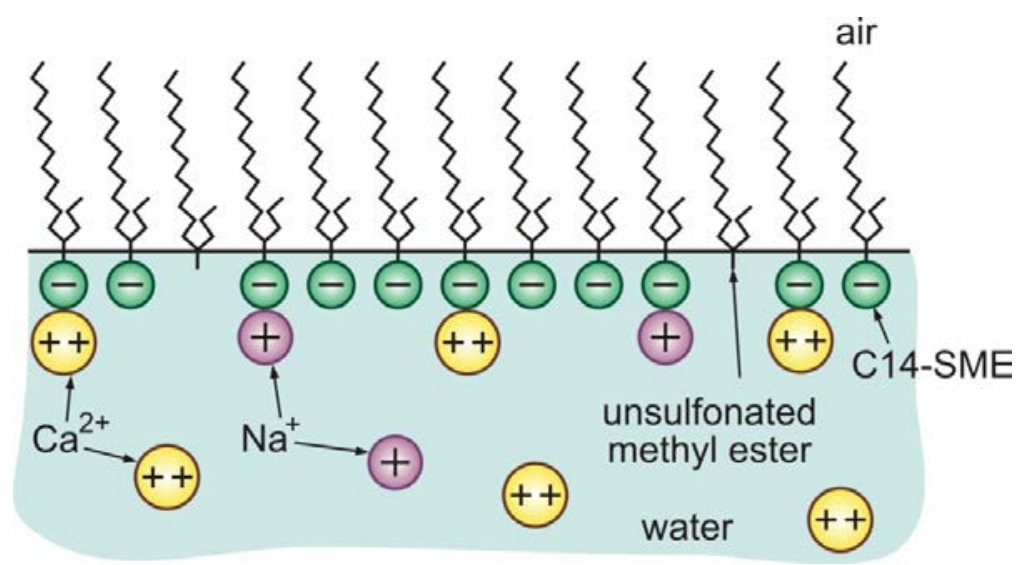

(b)

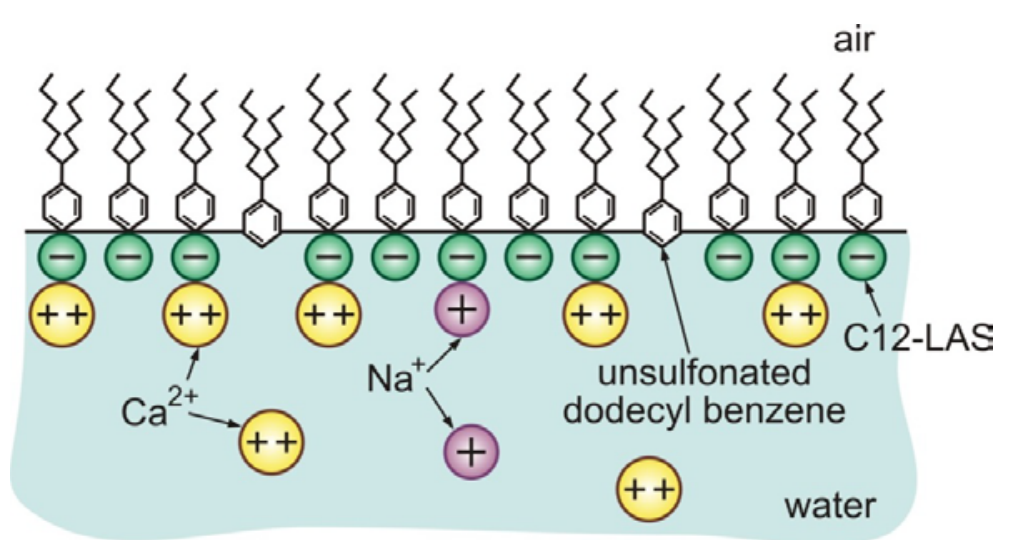

Fig. 3. Sketch of adsorption layers of (a) C14-SME and (b) C12-LAS in the presence of $\mathrm{Na}^{+}$ and $\mathrm{Ca}^{2+}$ counterions and nonionic admixtures from unsulfonated surfactant molecules.

For this purpose, the adsorption isotherms that describe the chemical equilibrium between the bulk solution and the adsorption layer (with respect to the exchange of each adsorbing component) are considered as a system of equations, which is solved numerically and the obtained theoretical curves are compared with the experimental data. For the surface active components, adequate theoretical description is provided by the van der Waals model, which treats the adsorption layer as a two-dimensional gas of interacting molecules (non-localized adsorption). The binding of counterions (such as $\mathrm{Na}^{+}$and $\mathrm{Ca}^{2+}$ ) to the surfactant headgroups in the adsorption layer (Fig. 3) is described by Stern isotherms (Langmuirian localized adsorption) [17-22]. Following the approach developed in Ref. [20], below we formulate the basic equations. 
For convenience, the components will be numbered in the following way: 1 - surfactant anion (Cn-SME, LAS); $2-\mathrm{Na}^{+}$counterion; $3-\mathrm{Cl}^{-}$coion; $4-\mathrm{Ca}^{2+}$ counterion; $\mathrm{n}-$ nonionic admixture (Cn-ME, LAB). The van der Waals adsorption isotherms for the surfactant and nonionic admixture are as follows [20,23]:

$$
\begin{aligned}
& K \gamma_{ \pm} c_{1} \exp \left(-\Phi_{\mathrm{s}}\right)=\frac{\alpha_{11} \Gamma_{1}}{1-\alpha\left(\Gamma_{1}+\Gamma_{\mathrm{n}}\right)} \\
& \times \exp \left[\frac{\left(2 \alpha_{11}-\alpha\right) \Gamma_{1}+\left(2 \alpha_{1 \mathrm{n}}-\alpha\right) \Gamma_{\mathrm{n}}}{1-\alpha\left(\Gamma_{1}+\Gamma_{\mathrm{n}}\right)}-\frac{2\left(\beta_{11} \Gamma_{1}+\beta_{1 \mathrm{n}} \Gamma_{\mathrm{n}}\right)}{k T}\right] \\
& K_{\mathrm{n}} c_{\mathrm{n}}=\frac{\alpha_{\mathrm{nn}} \Gamma_{\mathrm{n}}}{1-\alpha\left(\Gamma_{1}+\Gamma_{\mathrm{n}}\right)} \\
& \times \exp \left[\frac{\left(2 \alpha_{1 \mathrm{n}}-\alpha\right) \Gamma_{1}+\left(2 \alpha_{\mathrm{nn}}-\alpha\right) \Gamma_{\mathrm{n}}}{1-\alpha\left(\Gamma_{\mathrm{n}}+\Gamma_{\mathrm{n}}\right)}-\frac{2\left(\beta_{1 \mathrm{n}} \Gamma_{1}+\beta_{\mathrm{nn}} \Gamma_{\mathrm{n}}\right)}{k T}\right]
\end{aligned}
$$

Here, $k$ is the Boltzmann constant; $T$ is the temperature; $c_{1}$ and $c_{\mathrm{n}}$ are the bulk concentrations of the respective components; $\Gamma_{1}$ and $\Gamma_{\mathrm{n}}$ are their adsorptions; $\Phi_{\mathrm{s}}=e\left|\psi_{\mathrm{s}}\right| /(k T)$ is the dimensionless surface electric potential; $\psi_{\mathrm{s}}$ is the dimensional potential; $e$ is the elementary electric charge; $\gamma_{ \pm}$is the activity coefficient;

$$
\alpha=\sum_{i, j=1, \mathrm{n}} \alpha_{i j} X_{i} X_{j}, \quad \beta=\sum_{i, j=1, \mathrm{n}} \beta_{i j} X_{i} X_{j}, \quad X_{i}=\frac{\Gamma_{i}}{\Gamma_{1}+\Gamma_{\mathrm{n}}}
$$

$\alpha_{i j}=\alpha_{j i}$ and $\beta_{i j}=\beta_{j i}(i, j=1, \mathrm{n})$ are constant parameters. In particular, $\alpha_{i j}$ are excluded areas per headgroup and $\beta_{i j}$ are interaction parameters for the respective pairs of components at the interface [20,23]; the adsorption parameter for the nonionic component, $K_{\mathrm{n}}$, is constant, whereas the adsorption parameter of the ionic surfactant is given by the expression [17]:

$$
K=K_{1}\left[1+K_{\mathrm{St}, 2} \gamma_{ \pm} c_{2} \exp \left(\Phi_{\mathrm{s}}\right)+K_{\mathrm{St}, 4} \gamma_{ \pm} c_{4} \exp \left(2 \Phi_{\mathrm{s}}\right)\right]
$$

where $K_{1}$ is the adsorption contact of this surfactant; $K_{\mathrm{St}, 2}$ and $K_{\mathrm{St}, 4}$ are the Stern constants of the respective counterions. The Stern adsorption isotherms, which describe the binding of $\mathrm{Na}^{+}$ and $\mathrm{Ca}^{2+}$ counterions, are as follows [17]:

$$
\begin{aligned}
& \frac{\Gamma_{2}}{\Gamma_{1}}=\frac{K_{\mathrm{St}, 2} \gamma_{ \pm} c_{2} \exp \left(\Phi_{\mathrm{s}}\right)}{1+K_{\mathrm{St}, 2} \gamma_{ \pm} c_{2} \exp \left(\Phi_{\mathrm{s}}\right)+K_{\mathrm{St}, 4} \gamma_{ \pm} c_{4} \exp \left(2 \Phi_{\mathrm{s}}\right)} \\
& \frac{\Gamma_{4}}{\Gamma_{1}}=\frac{K_{\mathrm{St}, 4} \gamma_{ \pm} c_{4} \exp \left(2 \Phi_{\mathrm{s}}\right)}{1+K_{\mathrm{St}, 2} \gamma_{ \pm} c_{2} \exp \left(\Phi_{\mathrm{s}}\right)+K_{\mathrm{St}, 4} \gamma_{ \pm} c_{4} \exp \left(2 \Phi_{\mathrm{s}}\right)}
\end{aligned}
$$


where $c_{2}$ and $c_{4}$ are the bulk concentrations of $\mathrm{Na}^{+}$and $\mathrm{Ca}^{2+}$ ions, whereas $\Gamma_{2}$ and $\Gamma_{4}$ are the adsorptions of $\mathrm{Na}^{+}$and $\mathrm{Ca}^{2+}$ ions in the Stern layer. It can be proven that the above surfactantadsorption and counterion-binding isotherms are thermodynamically compatible, that is the Euler condition, Eq. (5.3) in Ref. [17], is satisfied. To close the system of equations, we need also the relation between surface electric charge and potential (the Gouy or Graham equation), which has the following form for a mixture of 1:1 and 2:1 electrolytes [17]:

$$
\Gamma_{1}-\Gamma_{2}-2 \Gamma_{4}=\frac{4 I}{\kappa} \sinh \left(\frac{\Phi_{\mathrm{s}}}{2}\right) g
$$

Here, $\kappa$ is the Debye screening parameter; $I$ is the solution's ionic strength; $g$ is defined as follows:

$$
g=\left(1-\lambda^{2}+\lambda^{2} y^{2}\right)^{1 / 2}, \quad \lambda=\left(\frac{c_{4}}{I}\right)^{1 / 2}, \quad y=\exp \left(\frac{\Phi_{\mathrm{s}}}{2}\right)
$$

For the considered system, the ionic strength is:

$$
I=c_{2}+3 c_{4}
$$

and the parameters $\gamma_{ \pm}$and $\kappa$ can be calculated from the expressions [17,24]:

$$
\log _{10} \gamma_{ \pm}=0.055 I-\frac{0.5115 \sqrt{I}}{1+1.316 \sqrt{I}}, \frac{1}{\kappa}=\frac{0.304}{\sqrt{I}}(\mathrm{~nm})
$$

Here, the dimension of $I$ is $\mathrm{mol} / \mathrm{L}$; as usual, $\gamma_{ \pm}$is dimensionless.

Equations (1), (2), (5), (6) and (7) form a system of five equations for determining the five unknown quantities $\Gamma_{1}, \Gamma_{2}, \Gamma_{4}, \Gamma_{\mathrm{n}}$ and $\Phi_{\mathrm{s}}$ for each given combination of bulk concentrations, $c_{1}, c_{2}, c_{4}$ and $c_{\mathrm{n}}$. This system is to be solved numerically. The principles of the computational procedure are described in Section 5.2 of Ref. [20].

Having determined $\Gamma_{1}, \Gamma_{\mathrm{n}}$ and $\Phi_{\mathrm{s}}$, one can further calculate the surface tension [20]:

$$
\sigma=\sigma_{0}-\frac{k T\left(\Gamma_{1}+\Gamma_{\mathrm{n}}\right)}{1-\alpha\left(\Gamma_{1}+\Gamma_{\mathrm{n}}\right)}+\beta\left(\Gamma_{1}+\Gamma_{\mathrm{n}}\right)^{2}-2 k T F
$$

where $\sigma_{0}$ is the surface tension in the absence of adsorbed species, and the function $F$ is defined as follows [17]:

$$
F=\frac{I}{\kappa}\left[\left(y+\frac{2}{y}\right) g-3+\frac{1-3 \lambda^{2}}{\lambda} \ln \left(\frac{\lambda y+g}{\lambda+1}\right)\right] \text { for } c_{4} \neq 0
$$


In Eq. (12), the dimension of $I$ is $\mathrm{m}^{-3}$. In the special case $c_{4} \rightarrow 0$, Eq. (12) reduces to:

$$
F=\frac{4 I}{\kappa}\left[\cosh \left(\frac{\Phi_{\mathrm{s}}}{2}\right)-1\right] \text { for } c_{4}=0
$$

For the nonionic admixture in the ionic surfactant, we can use the relation

$$
c_{\mathrm{n}}=x_{\mathrm{n}} c_{1}
$$

where $x_{\mathrm{n}}$ is the relative molar content of the nonionic admixture. It should be noted that in the above system of equations, $x_{\mathrm{n}}$ appears only in the product $K_{\mathrm{n}} X_{\mathrm{n}}$ in the left-hand side of Eq. (2). For this reason, in the fits of experimental data the product $K_{\mathrm{n}} X_{\mathrm{n}}$ is treated as an adjustable parameter, which is determined from the best fit together with $K_{1}$. Furthermore, if $K_{\mathrm{n}}$ is not known, one could estimate $x_{\mathrm{n}}$ by setting $K_{\mathrm{n}} \approx K_{1}$, which is a reasonable approximation [13].

\subsection{Comparison of theory and experiment}

In the calculations, it is convenient to use dimensionless interaction parameters:

$$
\hat{\beta}_{11}=\frac{2 \beta_{11}}{\alpha_{11} k T}, \quad \hat{\beta}_{1 \mathrm{n}}=\frac{2 \beta_{1 \mathrm{n}}}{\alpha_{11} k T}, \quad \hat{\beta}_{\mathrm{nn}}=\frac{2 \beta_{\mathrm{nn}}}{\alpha_{\mathrm{nn}} k T}
$$

The following relations have been also used [20,23]:

$$
\hat{\beta}_{1 \mathrm{n}}=\hat{\beta}_{11}\left(\frac{\alpha_{11}}{\alpha_{1 \mathrm{n}}}\right)^{3 / 2}, \quad \alpha_{1 \mathrm{n}}=\left(\frac{\sqrt{\alpha_{11}}+\sqrt{\alpha_{\mathrm{nn}}}}{2}\right)^{2}
$$

The unsulfonated admixtures, which have a very low solubility in water, are expected to undergo a surface phase transition if spread in a monolayer at the air/water interface (like the fatty acids with $n \geq 12$ [25]). For this reason, we have set $\hat{\beta}_{\mathrm{nn}}=3^{3} / 2^{2}=6.75$, which corresponds to the onset of phase transition in the van der Waals model [26]. By molecular size considerations, one can estimate $\alpha_{\mathrm{nn}}=22.6 \AA^{2}$ for Cn-ME [13] and $\alpha_{\mathrm{nn}}=35.6 \AA^{2}$ for LAB [21].

First, a family of experimental surface-tension isotherms, corresponding to different $\mathrm{NaCl}$ concentrations, have been fitted with the theoretical model and the values of the adjustable parameters $\alpha_{11}, K_{1}, K_{\mathrm{n}} x_{\mathrm{n}}, \hat{\beta}_{11}$, and $K_{\mathrm{St}, 2}$ have been determined from the best fit. Next, the surface tension isotherm obtained in the presence of $\mathrm{CaCl}_{2}$ (Fig. 2) has been fitted 
by using only one adjustable parameter, $K_{\mathrm{St}, 4}$, which is determined from the respective best fit.

In our case, we proceeded in the following way. First, surface tension isotherms for pure $\left(x_{\mathrm{n}}=0\right)$ sodium lauryl sulfonate were fitted in Ref. [13]; the determined parameter values are shown in Table 1 . With the obtained value of $K_{\mathrm{St}, 2}$ (binding constant of $\mathrm{Na}^{+}$ions to the sulfonate headgroup) we further fitted the families of experimental surface-tension isotherms for C14-SME, C16-SME and LAS corresponding to different $\mathrm{NaCl}$ concentrations (Fig. 2). The values of the parameters $\alpha_{11}, K_{1}, K_{\mathrm{n}} x_{\mathrm{n}}$, and $\hat{\beta}_{11}$ determined in this way are also listed in Table 1. Finally, using the obtained $\alpha_{11}, K_{1}, K_{\mathrm{n}} x_{\mathrm{n}}$, and $\hat{\beta}_{11}$ we fitted the surface tension isotherm measured in the presence of $\mathrm{CaCl}_{2}$ and determined $K_{\mathrm{St}, 4}$ for C14-SME, C16-SME and LAS (Table 1). The best theoretical curves shown in Fig. 2 are in excellent agreement with the experimental data. The fits for C14- and C16-SME with/without $\mathrm{NaCl}$ have been drawn in our previous paper [13], whereas all other fits in Fig. 2 are obtained in the present study.

Table 1. Adsorption parameters of $\mathrm{Cn}$-SME and LAS, including the Stern (binding) constants $K_{\mathrm{St}, 2}$ for $\mathrm{Na}^{+}$ions and $K_{\mathrm{St}, 4}$ for $\mathrm{Ca}^{2+}$ ions.

\begin{tabular}{|l|l|l|l|l|l|l|l|}
\hline Surfactant & $\begin{array}{l}\alpha_{11} \\
\left(\AA^{2}\right)\end{array}$ & $K_{1}\left(\mathrm{M}^{-1}\right)$ & $\begin{array}{l}K_{\mathrm{n}} x_{\mathrm{n}} \\
\left(\mathrm{M}^{-1}\right)\end{array}$ & $\hat{\beta}_{11}$ & $K_{\mathrm{St}, 2}\left(\mathrm{M}^{-1}\right)$ & $K_{\mathrm{St}, 4}\left(\mathrm{M}^{-1}\right)$ & $E_{4} / k T$ \\
\hline C12-SO3* & 37 & $8.86 \times 10^{4}$ & - & 1.61 & 2.86 & - & - \\
\hline C14-SME & 37 & $5.74 \times 10^{5}$ & $1.11 \times 10^{2}$ & 1.74 & 2.86 & 2.00 & 2.39 \\
\hline C16-SME & 37 & $5.54 \times 10^{6}$ & $5.66 \times 10^{2}$ & 1.98 & 2.86 & 2.00 & 2.39 \\
\hline LAS & 37 & $9.79 \times 10^{5}$ & $9.31 \times 10^{3}$ & 6.41 & 2.86 & 6.54 & 3.58 \\
\hline
\end{tabular}

*C12-SO3 = sodium lauryl sulfonate

As seen in Table 1, the fits of the data for all investigated surfactants correspond to the same values $\alpha_{11}$ and $K_{\mathrm{St}, 2}$. As shown in Ref. [13], $\alpha_{11}=37 \AA^{2}$ represents the cross-sectional area of the hydrated sulfonate ion, which determines the area per molecule in a closely packed adsorption layer. The obtained excellent fits indicate that the cross-sectional area of the sulfonate headgroup turns out to be bigger than the area occupied by the hydrocarbon tails of the surfactant molecules (Fig. 3), and bigger than the area occupied by the benzene ring of LAS, which is $35.6 \AA^{2}$ [21]. Moreover, the fact that the values of the Stern constant $K_{\mathrm{St}, 2}$ are the same for the investigated surfactants means that the energy of binding of $\mathrm{Na}^{+}$counterions to the sulfonate headgroup is the same for all of them (see below). 
In Table 1, the values of the adsorption parameter $K_{1}$ increase with the rise of the hydrocarbon chainlength, as it should be expected $[20,25]$. This constant is related to the energy for transfer of the hydrocarbon tail from aqueous environment into the air upon adsorption. The value of $K_{1}$ for LAS, which includes a contribution from both the alkyl chain and benzene ring (see Figs. 1 and 3b), turns out to be intermediate between the values of $K_{1}$ for C14- and C16-SME.

The interaction parameter $\hat{\beta}_{11}$ characterizes the interaction between the tails of the surfactant molecules at the air/water interface, which is dominated by the van der Waals attraction $[17,20]$. The fact that for LAS $\hat{\beta}_{11}$ is markedly greater than for the other surfactants in Table 1 could be explained with the specific, denser conformation of the hydrophobic chains in the adsorption layer of LAS; compare Figs. 3a and b.

The fact that the fits of the surface-tension isotherms obtained in the presence of $\mathrm{Ca}^{2+}$ ions, drawn by varying only the single adjustable parameter $K_{\mathrm{St}, 4}$, are in excellent agreement with the experiment indicates that the used adsorption model, based on Eq. (6), is adequate. This model assumes that each $\mathrm{Ca}^{2+}$ ion binds to a single surfactant headgroup; see Fig. 3. In other words, each negatively charged headgroup represents an adsorption site (potential well) for the $\mathrm{Ca}^{2+}$ counterion. Hence, illustrations showing divalent $\mathrm{Ca}^{2+}$ ions that are connecting two monovalent surfactant headgroups turn out to be incorrect. If the $\mathrm{Ca}^{2+}$ ions were occupying two adsorption sites, then Eq. (6) should have a different form containing the square (rather than the first power) of $\Gamma_{1}$.

The values of the Stern constants, $K_{\mathrm{St}, 2}$ and $K_{\mathrm{St}, 4}$ in Table 1 show two interesting facts that deserve discussion. First, the fact that $K_{\mathrm{St}, 4}$ is smaller than $K_{\mathrm{St}, 2}$ for C14- and C16-SME (2.00 vs. $2.86 \mathrm{M}^{-1}$ ) means that the binding of the divalent Ca counterion to the headgroup of SME is weaker than the binding of the monovalent $\mathrm{Na}$ counterion. This fact could be attributed to a specific interaction of the $\mathrm{Ca}^{2+}$ ion with the methylated carboxyl group of SME (shield effect) [3].

Second, the $\mathrm{Ca}^{2+}$ ion binds considerably stronger to the sulfonate group of LAS as compared to the sulfonate group of Cn-SME $\left(K_{\mathrm{St}, 4}=6.54\right.$ vs. $\left.2.00 \mathrm{M}^{-1}\right)$. The greater $K_{\mathrm{St}, 4}$ for the $\mathrm{Ca}^{2+} / \mathrm{LAS}$ pair seems to be a specific interaction due to the benzene ring of LAS - an effect that could be a subject of quantum chemical computations. Whatever the origin of this effect could be, it leads to much easier precipitation of LAS by Ca ions, in comparison with SME. 
The used model includes competitive binding of $\mathrm{Na}^{+}$and $\mathrm{Ca}^{2+}$ ions to the surfactant headgroups. The binding energy, $E_{i}$, can be estimated from the expression $[17,20,27]$ :

$$
K_{\mathrm{St}, i}=\alpha_{11} \delta_{i} \exp \left(\frac{E_{i}}{k T}\right), \quad i=2,4
$$

$\delta_{i}$ is the diameter of the hydrated counterion in aqueous solution. For $\mathrm{Na}^{+}$and $\mathrm{Ca}^{2+}$ ions, we have, respectively, $\delta_{2}=7 \AA$ and $\delta_{4}=8.2 \AA$. Using the values of $\alpha_{11}, K_{\mathrm{St}, 2}$ and $K_{\mathrm{St}, 4}$ in Table 1, we calculate $E_{2}=2.91 \mathrm{kT}$ for $\mathrm{Na}^{+} /$sulfonate group; $E_{4}=2.39 \mathrm{kT}$ for $\mathrm{Ca}^{2+} / \mathrm{SME}$ and $E_{4}=3.58 k T$ for $\mathrm{Ca}^{2+} / \mathrm{LAS}$.

In view of the fact that $E_{2}=1.64 \mathrm{kT}$ for $\mathrm{Na}^{+} /$sulfate group [17,20,27], it turns out that the $\mathrm{Na}^{+}$ion binds stronger to the sulfonate group, as compared to the sulfate group. Thus, using the terminology introduced by Kunz et al. [28], we may conclude that the sulfonate group is "harder" than the sulfate group.

Finally, let us discuss the effect of nonionic admixtures on the obtained surface tension isotherms. It is known that even trace amounts of such admixtures essentially lower the surface tension of ionic surfactant solutions, the effect being stronger at lower ionic strengths $[20,21,29]$. Conversely, from the effect of the nonionic admixture on the surface tension one can determine the amount of this admixture in the basic ionic surfactant. From the fits of the surface-tension isotherms (Fig. 2), we determined the product $K_{\mathrm{n}} x_{\mathrm{n}}$ (Table 1) that enters the left-hand side of Eq. (2), where $c_{\mathrm{n}}=x_{\mathrm{n}} c_{1}$. Knowing $K_{\mathrm{n}}$, one can further estimate the relative molar content of the nonionic admixture, $x_{\mathrm{n}}$. Thus, from the values of $K_{\mathrm{n}} x_{\mathrm{n}}$ in Table 1 we estimated: $x_{\mathrm{n}}=0.017 \%$ for C14-SME; $x_{\mathrm{n}}=0.010 \%$ for C16-SME, and $x_{\mathrm{n}}=0.95 \%$ for LAS. The values of $x_{n}$ for $C_{n}$-SME have been reported in our previous study [13], whereas the value of $x_{\mathrm{n}}$ for LAS is estimated here using the approximation $K_{\mathrm{n}} \approx K_{1}$. The obtained values of $x_{\mathrm{n}}$ indicate that we are really dealing with trace amounts of nonionic admixture, which is the greatest for the used LAS sample.

\subsection{Numerical results and discussion}

Having determined the parameters of the model for SME and LAS (Table 1), we can further calculate (predict) the values of different parameters of the surfactant adsorption layer, such as surface tension, $\sigma$; surface electric potential, $\psi_{\mathrm{s}}$, and adsorptions of surfactant and counterions, $\Gamma_{1}, \Gamma_{2}$ and $\Gamma_{4}$. To compare the effects of $\mathrm{Na}^{+}$and $\mathrm{Ca}^{2+}$, Figures 4 and 5 show the 
calculated dependencies of the aforementioned parameters on the surfactant concentration at the same ionic strength of added electrolyte $\left(\mathrm{NaCl}\right.$ or $\left.\mathrm{CaCl}_{2}\right)$.

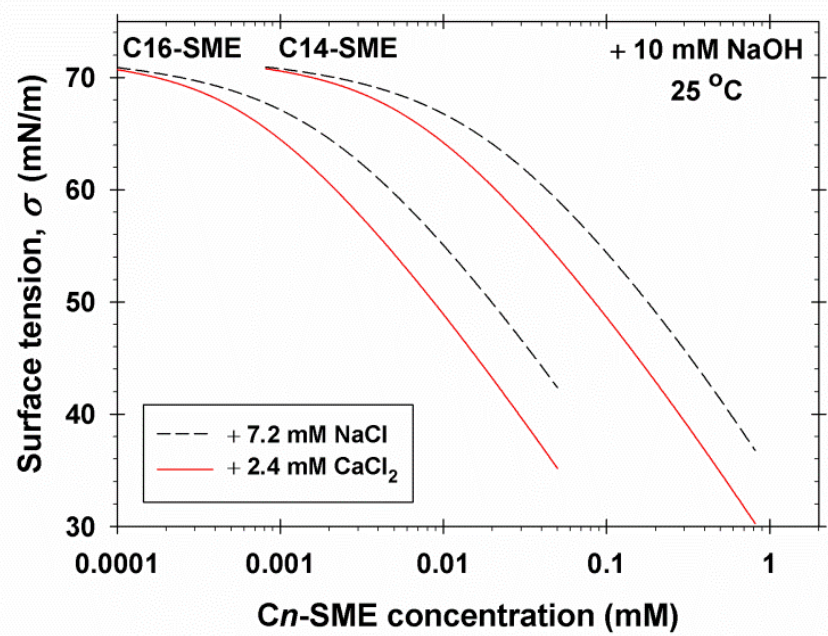

(a)

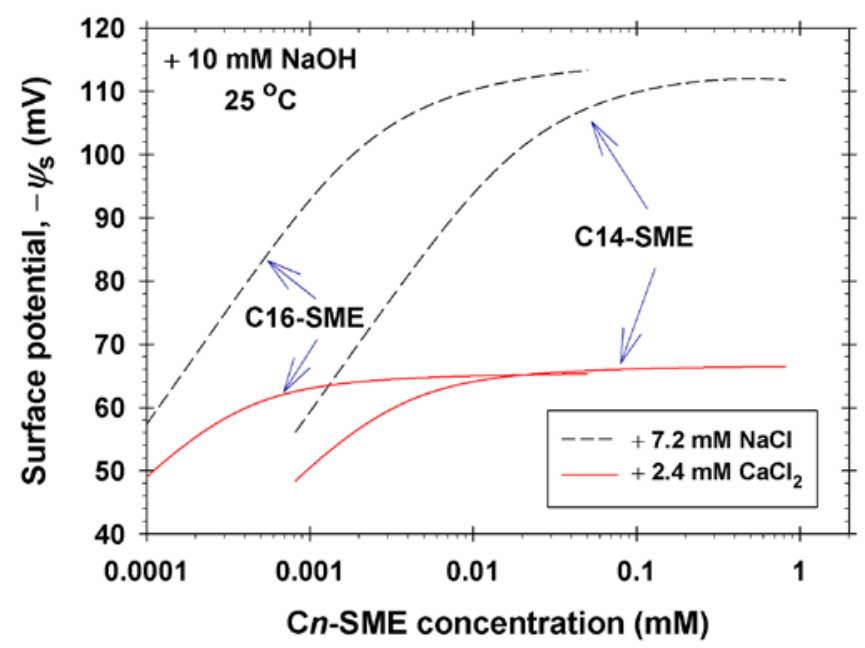

(c)

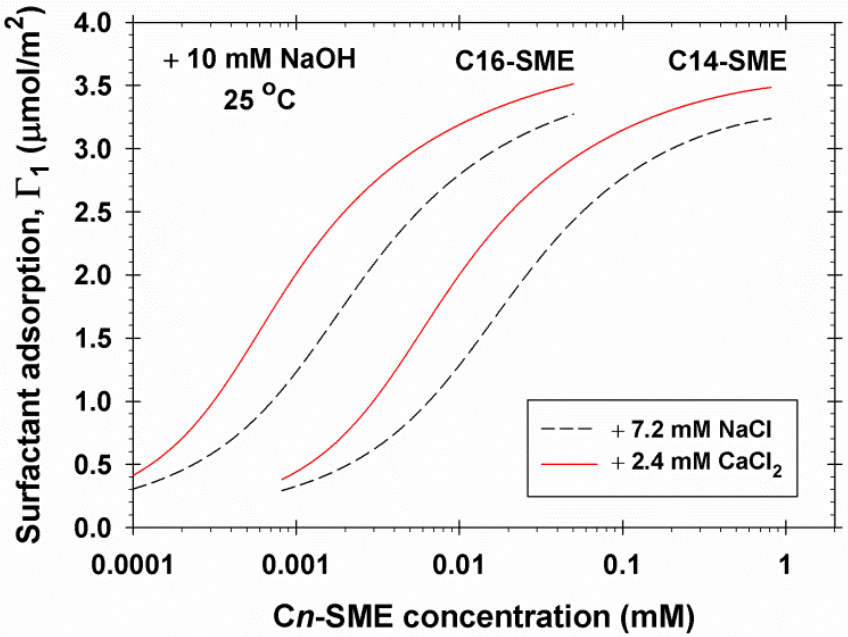

(b)

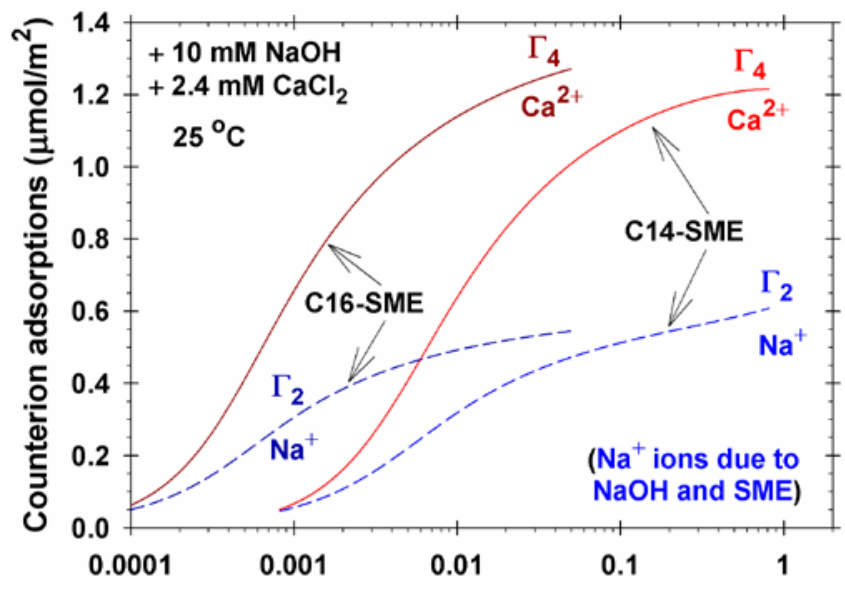

(d)

Cn-SME concentration (mM)

Fig. 4. Comparison of properties of surfactant adsorption layers from C14- and C16-SME at the air/water interface, calculated using parameter values from Table 1. (a) Surface tension, $\sigma$; (b) surfactant adsorption, $\Gamma_{1}$; (c) magnitude of the surface electric potential, $-\psi_{\mathrm{s}}$, and (d) adsorptions of $\mathrm{Na}^{+}$and $\mathrm{Ca}^{2+}$ counterions in the Stern layer, $\Gamma_{2}$ and $\Gamma_{4}$, respectively, all of them as functions of the surfactant concentration. All curves end at the CMC.

The curves in Figures 4 and 5 refer to the real surfactants (with nonionic admixtures) used in our experiments; see Fig. 2. The values of $K_{\mathrm{n}} x_{\mathrm{n}}$ from Table 1 have been used and the adsorption of nonionic amphiphile, $\Gamma_{\mathrm{n}}$, has been also calculated; see Figure A1 in Appendix A. 
Figs. 4a and b show plots of $\sigma$ and $\Gamma_{1}$ vs. the concentration of C14- and C16-SME below the CMC. The concentration of $2.4 \mathrm{mM} \mathrm{CaCl}_{2}$ corresponds to very hard water, and the concentration of $7.2 \mathrm{mM} \mathrm{NaCl}$ corresponds to $1: 1$ salt solution of the same ionic strength.

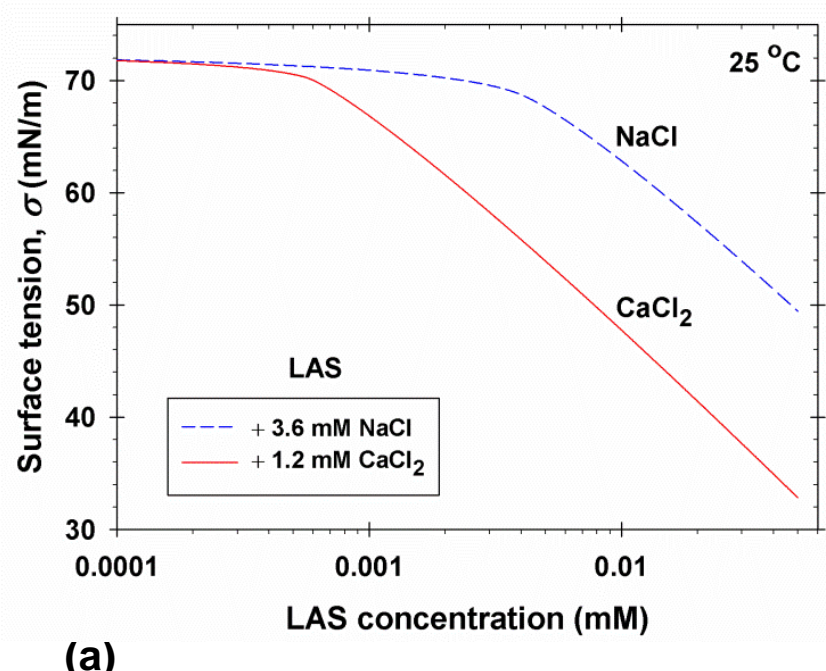

(a)

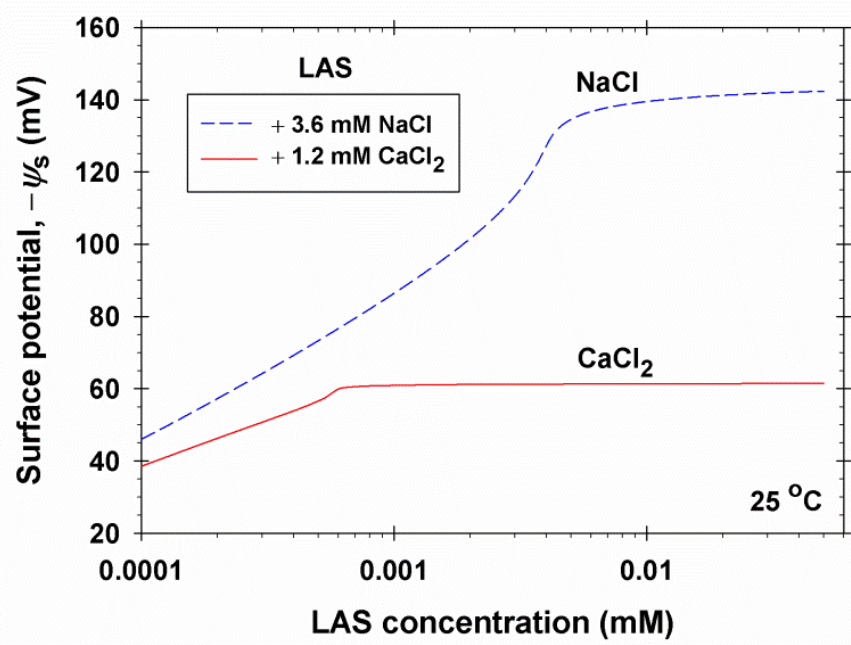

(c)

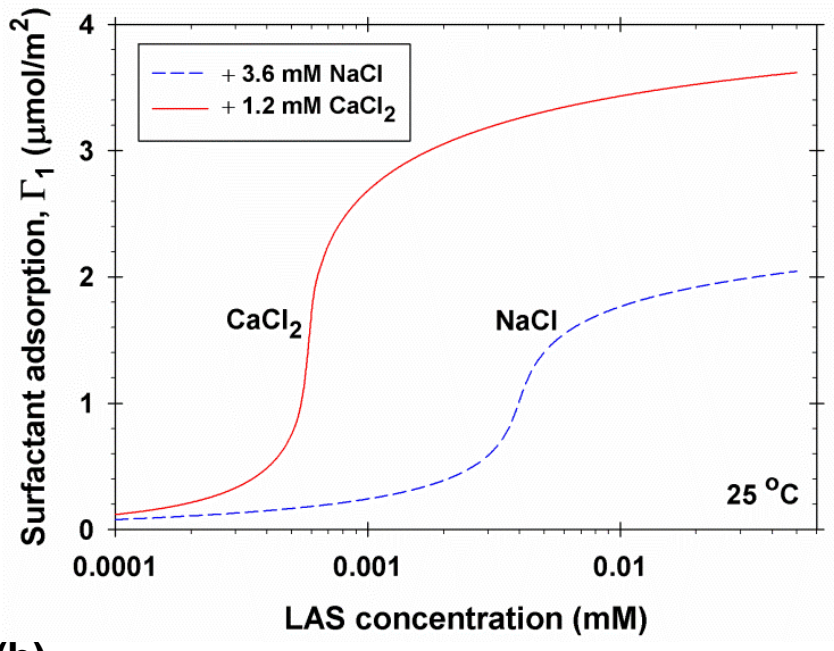

(b)

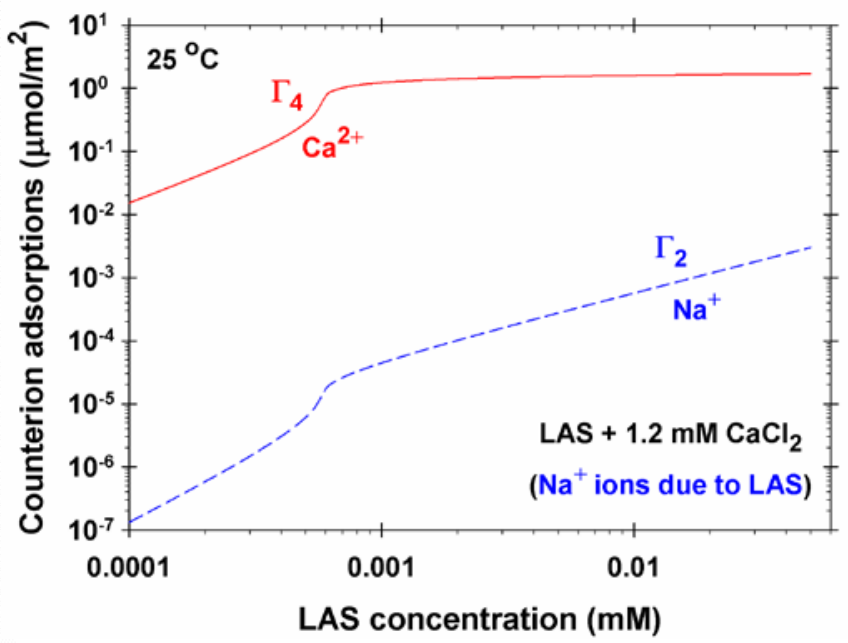

(d)

Fig. 5. Comparison of properties of surfactant adsorption layers from LAS at the air/water interface in the presence of $\mathrm{Na}^{+}$and $\mathrm{Ca}^{2+}$ ions calculated using parameter values from Table 1 . (a) Surface tension, $\sigma$; (b) surfactant adsorption, $\Gamma_{1}$; (c) magnitude of the surface electric potential, $-\psi_{\mathrm{s}}$, and (d) adsorptions of $\mathrm{Na}^{+}$and $\mathrm{Ca}^{2+}$ counterions in the Stern layer, $\Gamma_{2}$ and $\Gamma_{4}$, respectively, all of them as functions of the LAS concentration. All curves end at the CMC.

By shape, the curves for C14-SME are very similar to those for C16-SME, but they are shifted to the right with ca. one order of magnitude due to the shorter alkyl chain of C14SME. At the same ionic strength, the $\mathrm{Ca}^{2+}$ ions lead to a pronounced decrease of $\sigma$, with $7 \mathrm{mN} / \mathrm{m}$ at the CMC, as compared to the curve for $\mathrm{Na}^{+}$. Correspondingly, the surfactant adsorption, $\Gamma_{1}$ (Fig. $4 \mathrm{~b}$ ) is higher in the presence of $\mathrm{Ca}^{2+}$ ions. The value of $\Gamma_{1}$ at the CMC is 
$3.5 \mu \mathrm{mol} / \mathrm{m}^{2}$ (47 $\AA^{2}$ per molecule), which is lower than $\Gamma_{1}$ at close packing (37 $\AA^{2}$ per molecule). The higher surfactant adsorption in the presence of $\mathrm{Ca}^{2+}$ ions is due to the more effective screening of the surface electric potential, $\psi_{\mathrm{s}}$, by these divalent counterions; see Fig. 4c. Indeed, the greatest value of $\left|\psi_{\mathrm{s}}\right|$ is $113 \mathrm{mV}$ in the presence of $\mathrm{Na}^{+}$, whereas it is only 66 $\mathrm{mV}$ in the presence of $\mathrm{Ca}^{2+}$ at the same ionic strength.

Fig. $4 \mathrm{~d}$ compares the adsorption (binding) of $\mathrm{Na}^{+}$and $\mathrm{Ca}^{2+}$ ions in the Stern layer. The calculated curves correspond to solutions that contain $2.4 \mathrm{mM} \mathrm{CaCl}_{2}$ and $10 \mathrm{mM} \mathrm{NaOH}$. In other words, the solutions contain a bulk concentration of $2.4 \mathrm{mM} \mathrm{Ca}^{2+}$, whereas the bulk concentration of $\mathrm{Na}^{+}$is slightly higher than $10 \mathrm{mM}$, with a main contribution from the $\mathrm{NaOH}$ and a smaller contribution from SME. We are dealing with competitive binding of $\mathrm{Na}^{+}$and $\mathrm{Ca}^{2+}$ counterions at the surfactant headgroups. It is remarkable that the adsorption of the $\mathrm{Ca}^{2+}$ ions is considerably greater than that of the $\mathrm{Na}^{+}$ions despite their lower bulk concentration and smaller binding constant - compare $K_{\mathrm{St}, 4}$ with $K_{\mathrm{St}, 2}$ in Table 1 . In such case, the only reason for the fact that $\Gamma_{4}>\Gamma_{2}$ (Fig. 4d) is that the subsurface concentration of the divalent $\mathrm{Ca}^{2+}$ ions is much higher than that of the monovalent $\mathrm{Na}^{+}$ions. Mathematically, this difference is expressed by the Boltzmann factors $\exp \left(\Phi_{s}\right)$ and $\exp \left(2 \Phi_{s}\right)$ in the numerators of Eqs. (5) and (6), respectively. At the higher surfactant concentrations, where $\left|\psi_{\mathrm{s}}\right|=66 \mathrm{mV}$ (Fig. 4c), their ratio is $\exp \left(\Phi_{\mathrm{s}}\right) \approx 13$, which explains the difference between the binding of $\mathrm{Ca}^{2+}$ and $\mathrm{Na}^{+}$and ions to the headgroups of SME.

Figs. 5a,b,c compare the dependencies of $\sigma, \Gamma_{1}$ and $\psi_{\mathrm{s}}$ on the surfactant concentration for adsorption layers of LAS in the presence of $1.2 \mathrm{mM} \mathrm{CaCl}_{2}$ and $3.6 \mathrm{mM} \mathrm{NaCl}$, i.e. at the same ionic strength of added surfactant. The comparison between the analogous curves in Figs. 4 and 5 indicates that, in general, the effect of $\mathrm{Ca}^{2+}$ ions (relative to that of the $\mathrm{Na}^{+}$ions) is much stronger for LAS as compared to SME. In particular, at $0.05 \mathrm{mM}$ LAS the value of $\sigma$ is with $16.6 \mathrm{mN} / \mathrm{m}$ lower in the presence of $\mathrm{Ca}^{2+}$ as compared to the curve with $\mathrm{Na}^{+}$(Fig. 5a). Likewise, for $\mathrm{CaCl}_{2} \Gamma_{1}$ rises up to $3.62 \mu \mathrm{mol} / \mathrm{m}^{2}$ (46 $\AA^{2}$ per molecule) vs. $2.05 \mu \mathrm{mol} / \mathrm{m}^{2}$ (81 $\AA^{2}$ per molecule) for $\mathrm{NaCl}$ (Fig. 5b). Especially strong is the effect of $\mathrm{Ca}^{2+}$ on the surface potential: at $0.05 \mathrm{mM}$ LAS we have $\left|\psi_{\mathrm{s}}\right|=61 \mathrm{mV}$ for $\mathrm{CaCl}_{2}$ vs. $142 \mathrm{mV}$ for $\mathrm{NaCl}$ (Fig. 5c). As illustrated in Fig. 5d, the $\mathrm{Ca}^{2+}$ ions completely dominate the counterion adsorption in the Stern layer.

As mentioned above, the strong effect of $\mathrm{Ca}^{2+}$ on the LAS adsorption layers is due to the combination of two factors acting in the same direction: (i) The binding energy of the $\mathrm{Ca}^{2+}$ ions to the surfactant headgroups is greater than that of the $\mathrm{Na}^{+}$ions (compare $K_{\mathrm{St}, 2}$ and $K_{\mathrm{St}, 4}$ 
in Table 1); (ii) At the same surface potential, the concentration of the divalent $\mathrm{Ca}^{2+}$ ions in the vicinity of the negatively charged surfactant adsorption layer is higher than that of the monovalent $\mathrm{Na}^{+}$ions

(a)

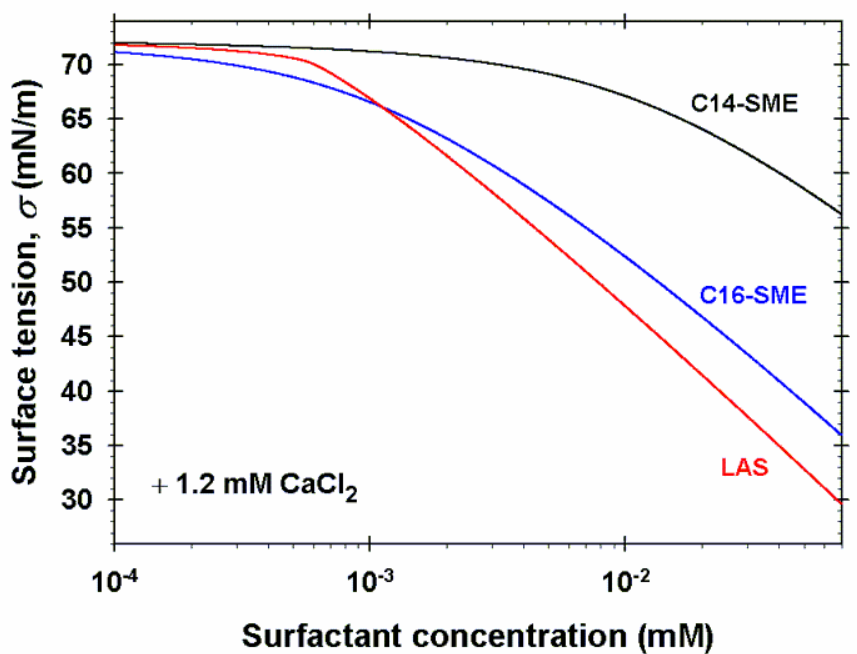

(b)

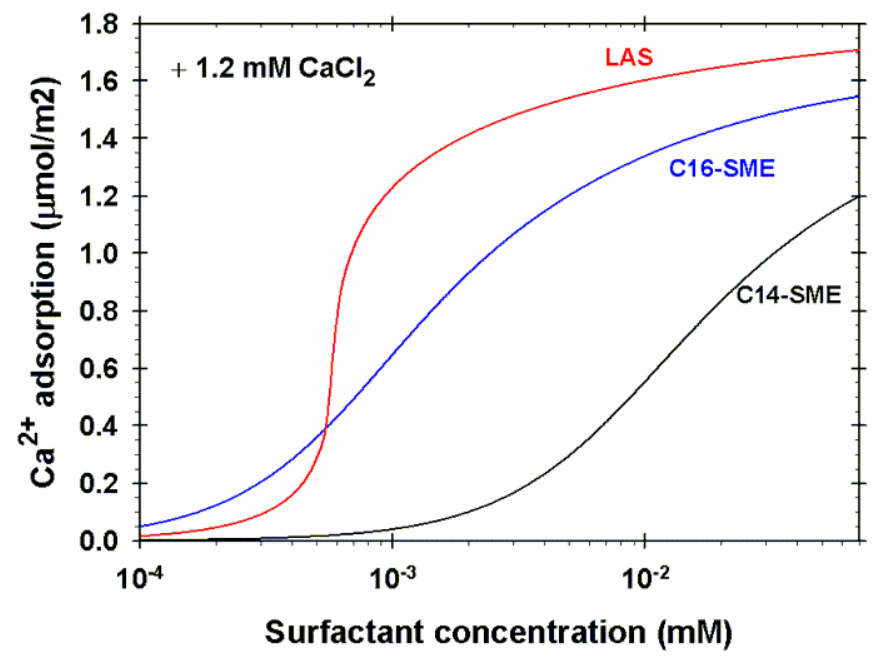

(c)

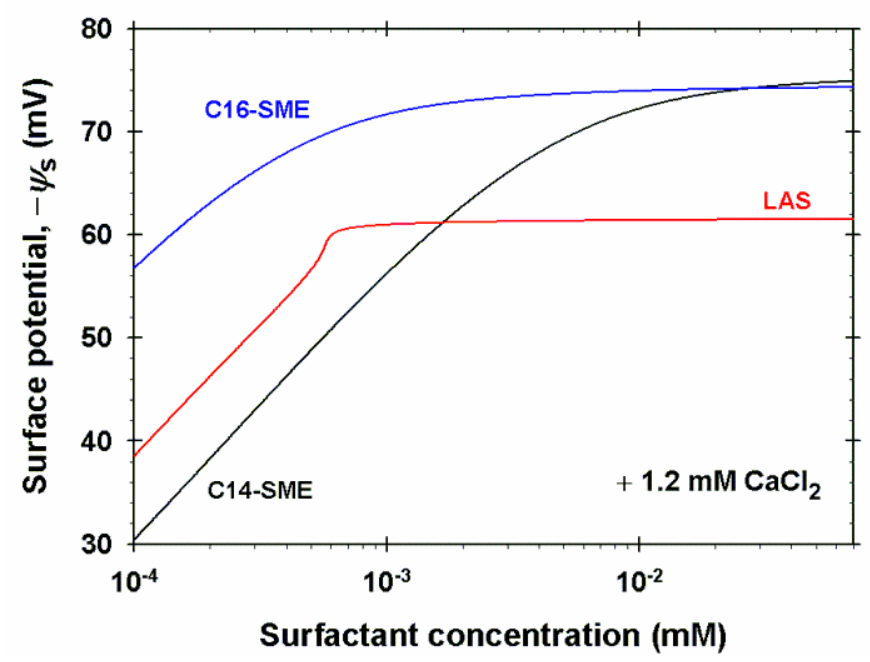

Fig. 6. Comparison of properties of surfactant adsorption layers from pure LAS, C14- and C16-SME at the air/water interface in the presence of $1.2 \mathrm{mM} \mathrm{CaCl}_{2}$ (moderately hard water) 
calculated using parameter values in Table 1. (a) Surface tension, $\sigma$; (b) surfactant adsorption, $\Gamma_{1}$; (c) magnitude of the surface electric potential, $-\psi_{\mathrm{s}}$, all of them as functions of the surfactant concentration.

Knowing the adsorption constants (Table 1), we can calculate also properties of the pure ionic surfactants, without any nonionic admixture ( $x_{\mathrm{n}}=0$; “computer purification”). Fig. 6 compares the values of $\sigma, \Gamma_{4}$ and $\psi_{\mathrm{s}}$ for pure C14-SME, C16-SME and LAS in the presence of $1.2 \mathrm{mM} \mathrm{CaCl}_{2}$. At the lowest surfactant concentration, the properties of the LAS adsorption layers are intermediate between those for C14- and C16-SME, which can be explained with the intermediate value of its adsorption constant, $K_{1}$; see Table 1 . However, at the higher surfactant concentrations, the stronger binding of $\mathrm{Ca}^{2+}$ ions to the LAS headgroups leads to extremal values for this surfactant: lowest surface tension (Fig. 6a); greatest $\mathrm{Ca}^{2+}$ binding (Fig. 6b), and lowest magnitude of the surface potential (Fig. 6c).

\section{Mixed surfactant solutions: surface tension and micellization}

Fig. 7 shows surface-tension data for mixed surfactant solutions: C14- with C16-SME (Fig. 7a); C14-SME with LAS (Fig. 7b), and C16-SME with LAS (Fig. 7c). The solutions contain added $\mathrm{NaOH}$ and $\mathrm{NaCl}$ to decrease the effect of the nonionic admixtures. Most different in their surface activity are C14- and C16-SME, which leads to the greatest effect of mixing on the surface tension (Fig. 7a). In contrast, the surface activities of C16-SME and LAS are closer, which leads to a relatively weak effect of mixing on $\sigma$ (Fig. 7c).

Fig. 8a shows data from Fig. 7a for the critical micellization concentration, $\mathrm{CMC}_{\mathrm{M}}$, of the mixed solutions of C14- and C16-SME. The data are plotted according to the known formula:

$\frac{1}{\mathrm{CMC}_{\mathrm{M}}}=\frac{x_{1}}{f_{1} \mathrm{CMC}_{1}}+\frac{1-x_{1}}{f_{2} \mathrm{CMC}_{2}}$

see e.g. [30,31]; $x_{1}$ and $x_{2}=1-x_{1}$ are the molar fractions of the monomers of the two surfactants; $\mathrm{CMC}_{1}$ and $\mathrm{CMC}_{2}$ are the CMCs of the separate surfactants; $f_{1}$ and $f_{2}$ are activity coefficients of the two components in the mixed micelles. In view of Eq. (18), the fact that the data in Fig. 8a complies with a straight line can be interpreted as ideal mixing of the two surfactants in the micelles, that is $f_{1}=f_{2}=1$. This is not surprising, because non-ideal mixing 
in micelles is typically observed when the mismatch between the paraffin chains of the two surfactants is greater than four $\mathrm{CH}_{2}$ groups [31,32]. 
(a)

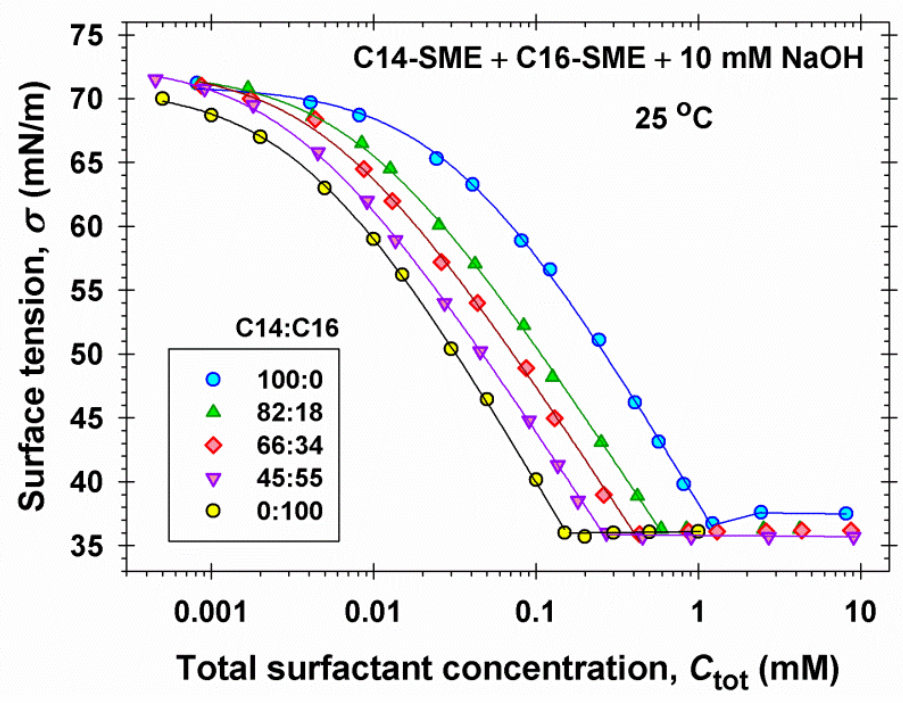

(b)

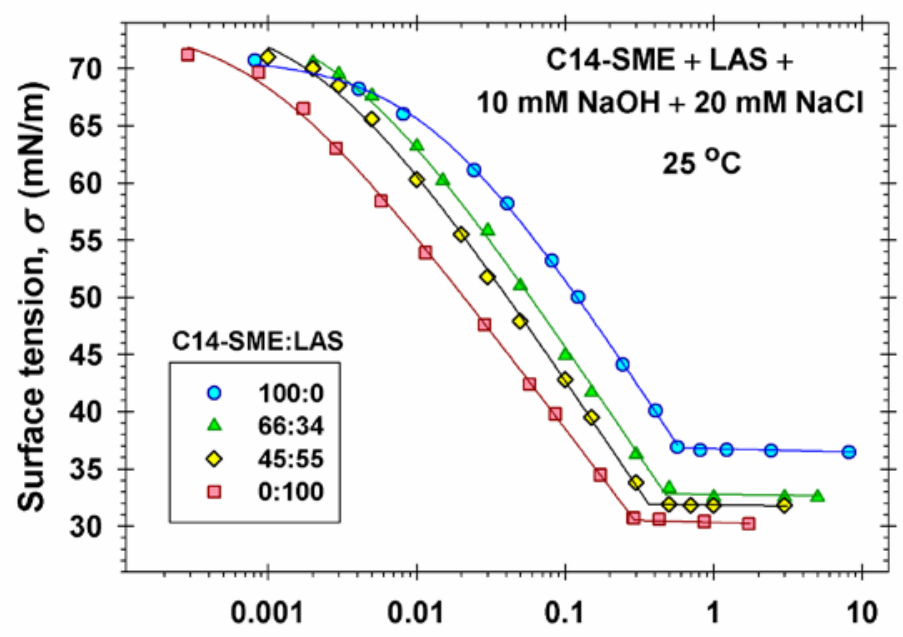

Total surfactant concentration, $C_{\text {tot }}(\mathrm{mM})$

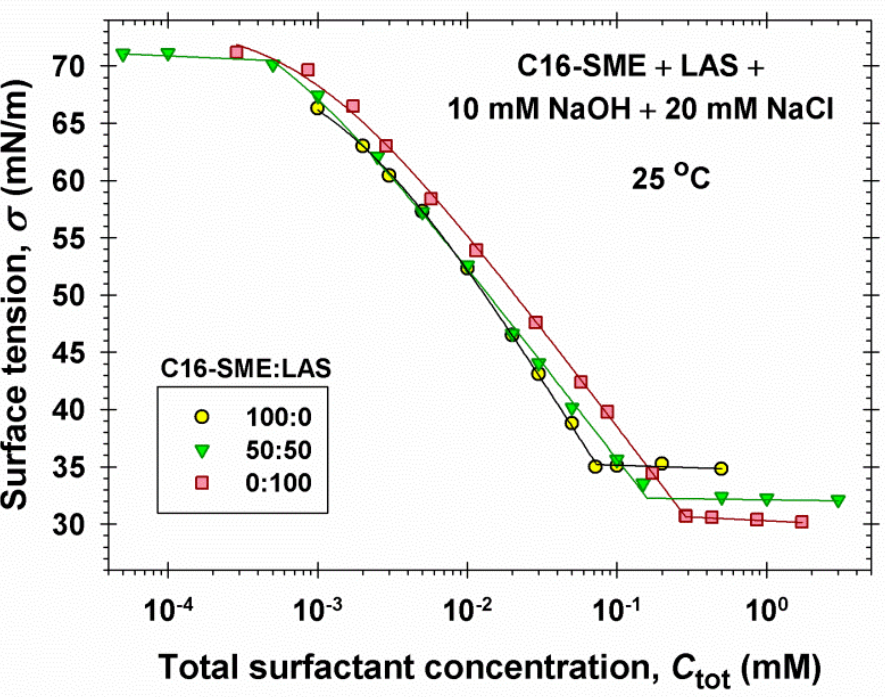

Fig. 7. Experimental data for the surface-tension, $\sigma$, of binary surfactant mixtures plotted vs. the total surfactant concentration, $C_{\text {tot }}$, at several different molar ratios shown in the figure: (a) C14- and C16-SME; (b) C14-SME and LAS, and (c) C16-SME and LAS. The lines are guides to the eye; their kinks correspond to the CMC. 

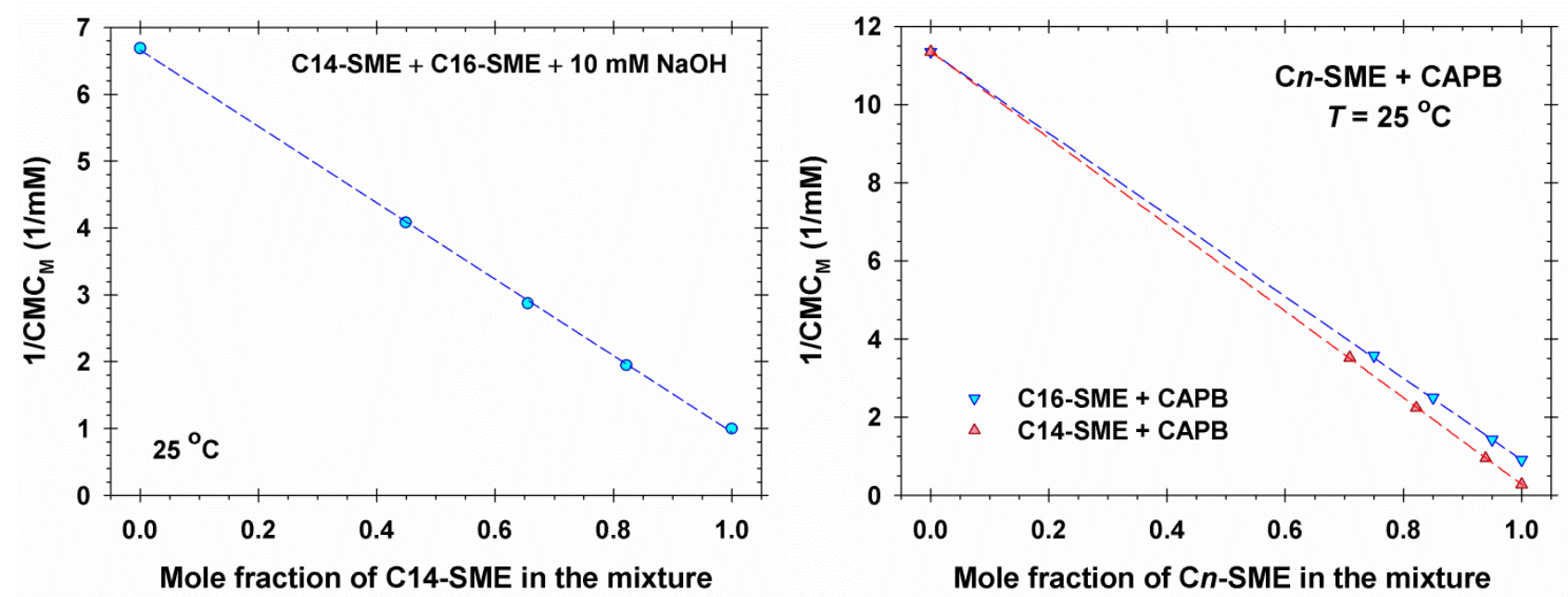

(a)

(b)
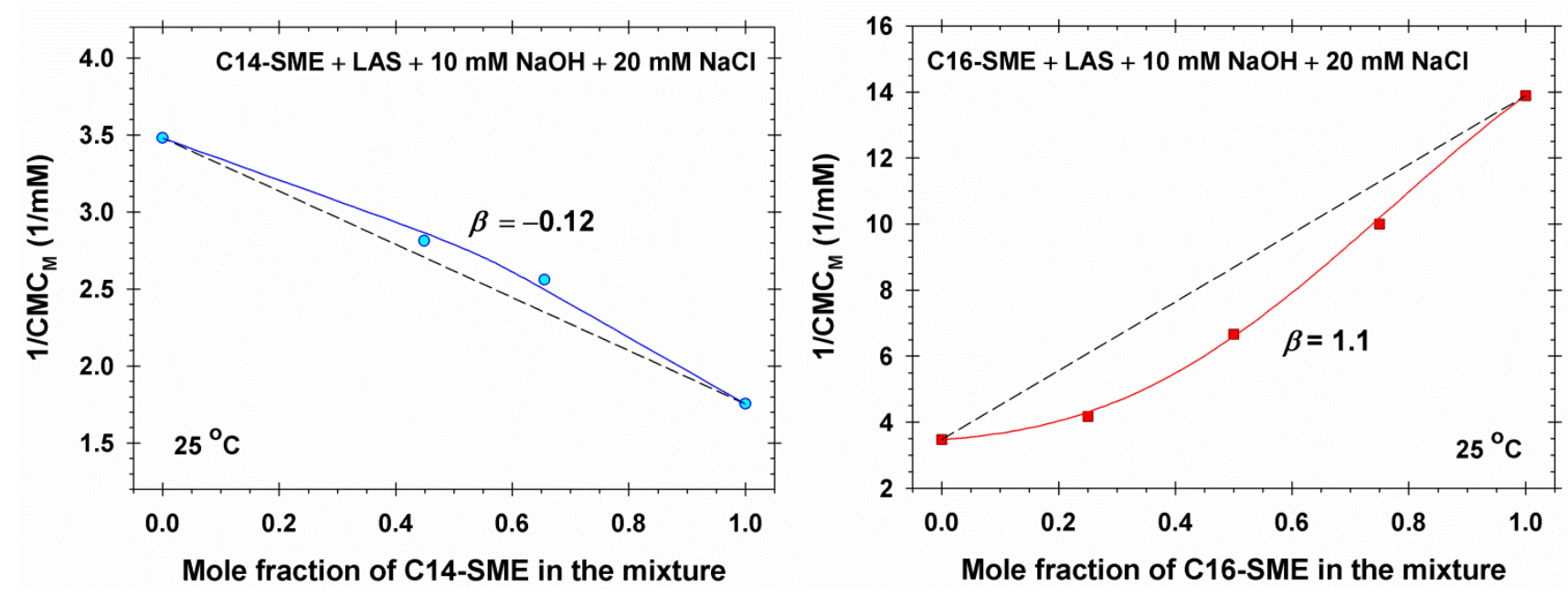

(c)

(d)

Fig. 8. Plots of $1 / \mathrm{CMC}_{\mathrm{M}}$ vs. the molar fraction of one of the two components in binary surfactant mixtures; $\mathrm{CMC}_{\mathrm{M}}$ is the critical micelle concentration of the mixed solution: (a) C14-SME + C16-SME; (b) C14-SME + CAPB and C16-SME + CAPB; (c) C14-SME + LAS, and (d) C16-SME + LAS. The dashed lines correspond to ideal mixing. The solid lines correspond to non-ideal mixing with interaction parameter $\beta$ denoted in the figure; details in the text.

Eq. (18) is rigorous for the mixed micelles of two nonionic surfactants. Generalization for ionic surfactants is also available [33]. However, Eq. (18) turns out to be applicable also to ionic surfactants as a nonionic approximation. Deviations from the nonionic approximation have been observed when the paraffin chain of one of the two surfactants contains $n \leq 10$ carbon atoms [34]. 
The linear dependencies in Fig. 8b indicate that the CMCs of the mixed solutions of C12- and C14-SME with CAPB also obey the ideal mixing law. Because of the very low CMC of CAPB, the critical micellization concentrations have been determined by electric conductivity measurements (Figs. A2 and A3 in Appendix A), rather than by surface-tension experiments. Due to the procedure of its synthesis, CAPB always contains an admixture of $\mathrm{NaCl}$. In our case, by conductivity measurements we established that $100 \mathrm{mM}$ CAPB contain $112 \mathrm{mM} \mathrm{NaCl}$. For this reason, accurate determination of CMC by conductivity was possible at the lower fractions of CAPB (Fig. 8b), at which the $\mathrm{NaCl}$ admixture in CAPB does not create a high background in conductivity.

The CMCs of the mixed solutions of C14-SME with LAS (Fig. 8c) and C16-SME with LAS (Fig. 8d) determined by surface-tension measurements show deviations from the ideal behavior. For the pair C14-SME/LAS the mixing leads to a weak synergistic effect, i.e. $\mathrm{CMC}_{\mathrm{M}}$ is lower than that in the case of ideal mixing. By contrast, for the pair C16-SME/LAS the mixing produces a weak antagonistic effect, i.e. $\mathrm{CMC}_{\mathrm{M}}$ is higher than for ideal mixing. Because the headgroups are identical, for the two considered surfactant pairs the deviations from ideality should be due to interactions between the surfactant tails in the micelle interior. Thermodynamically, these interactions can be characterized by the interaction parameter, $\beta$, which enters the expression for the activity coefficient that follows from the regular solution theory [26]:

$$
f_{i}=\exp \left[\beta\left(1-y_{i}\right)^{2}\right], \quad i=1,2
$$

$y_{1}$ and $y_{2}$ are the molar fractions of the two components in the micelles $\left(y_{1}+y_{2}=1\right)$. The definition of the interaction parameter is $\beta=-\left(w_{11}+w_{22}-2 w_{12}\right) c /(2 k T)$, where $w_{i j}$ is the energy of interaction between two neighboring molecules of components $i$ and $j$, and $c$ is the average number of closest neighbors of a given molecule in a micelle.

In general, the compositions of monomers and micelles are different, $x_{i} \neq y_{i}$. To determine $y_{1}$, we used the chemical-equilibrium relation between monomers and micelles with respect to component $i[30,31]$ :

$$
\ln \left(x_{i} \mathrm{CMC}_{\mathrm{M}}\right)=\ln \mathrm{CMC}_{i}+\ln \left[y_{i} f_{i}\left(y_{i}\right)\right], \quad i=1,2
$$

where $f_{i}\left(y_{i}\right)$ is given by Eq. (19). From the two expressions corresponding to $i=1$ and 2, $\mathrm{CMC}_{\mathrm{M}}$ can be eliminated: 


$$
\frac{x_{1}}{1-x_{1}}=\frac{\mathrm{CMC}_{1}}{\mathrm{CMC}_{2}} \frac{y_{1} f_{1}\left(y_{1}\right)}{y_{2} f_{2}\left(y_{2}\right)}
$$

$\left(y_{2}=1-y_{1}\right)$. In the numerical procedure, $\beta$ was treated as an adjustable parameter. For each given $\beta$ and $x_{1}$, Eq. (21) was solved numerically to determine $y_{1}$ and, next, $\mathrm{CMC}_{\mathrm{M}}$ was calculated from Eq. (18) along with Eq. (19). The values of $\beta$ determined from the best fits of the experimental data are shown in Figs. $8 \mathrm{c}$ and d.

\section{Conclusions}

In the present article, we compare the properties of sulfonated methyl esters of fatty acids (SME) and linear alkylbenzene sulfonate (LAS) in two respects: (i) effect of calcium ions on their surface tension and (ii) effect of composition on the CMC of their mixed aqueous solutions. The interpretation of surface tension isotherms of C14-SME, C16-SME and LAS obtained in the presence of $\mathrm{NaCl}$ and $\mathrm{CaCl}_{2}$ by means of theoretical model allowed us to determine the parameters that characterize the surfactant adsorption layers and counterion binding (Table 1). It turns out that the excluded area per molecule in the adsorption layer is the same for SME and LAS and is determined by the cross-sectional area of the sulfonate headgroup. The binding energy of $\mathrm{Na}^{+}$ions to the sulfonate headgroups of SME and LAS is also the same. However, the binding energy of the $\mathrm{Ca}^{2+}$ ion to the headgroup of LAS is considerably greater than that of SME, which is in agreement with the circumstance that LAS is precipitated by hard water [12]. In contrast, the binding energy of the $\mathrm{Ca}^{2+}$ ion to the headgroup of SME is smaller even than that of $\mathrm{Na}^{+}$, in accord with the reputation of SME as one of the most hardness tolerant surfactants [3]. Despite their lower binding energy, at the same bulk concentration the $\mathrm{Ca}^{2+}$ ions produce greater lowering of the surface tension of SME solutions than the $\mathrm{Na}^{+}$ions because of the higher subsurface concentration (and greater adsorption in the Stern layer) of the divalent calcium ions (Section 4).

The dependencies of the CMC on the composition of binary mixed surfactant solutions reveal that C14-SME and C16-SME exhibit ideal mixing. The same holds also for the mixed micelles of SME and CAPB. With respect to formation of mixed micelles, C14-SME and LAS exhibit slightly synergistic mixing, whereas C16-SME and LAS - antagonistic mixing, which is due to hydrocarbon-chain mismatch (Section 5).

The results in the present study allow prediction of the surface tension of solutions of SME and LAS in the presence of $\mathrm{Na}^{+}$and $\mathrm{Ca}^{2+}$ ions at various concentrations; contribute for a 
better understanding of the different tolerance of SME and LAS to hard water, and quantify the effect of composition on the CMC of binary surfactant mixtures containing SME.

\section{Acknowledgements}

The authors gratefully acknowledge the support from KLK OLEO. The C14-SME sample has been kindly provided by Dr. Hazimah Abu Hassan from MPOB. The authors thank Dr. Zlatina Mitrinova and Dr. Svetoslav Anachkov for the HPLC analysis of the LAS sample and Ms. Elka Basheva for determining the CMC of mixed SME + CAPB solutions by conductivity measurements.

\section{Appendix A. Supplementary material}

Supplementary data associated with this article can be found in the online version, at http://dx.doi.org/10.1016/j.colsurfa.2016.06.039

\section{References}

[1] L. Cohen, F. Trujillo, Performance of sulfoxylated fatty acid methyl esters, J. Surf. Deterg. 2 (1999) 363-365.

[2] L. Cohen, F. Soto, A. Melgarejo, D.W. Roberts, Performance of $\Phi$-sulfo fatty methyl ester sulfonate versus linear alkylbenzene sulfonate, secondary alkane sulfonate and $\alpha$ sulfo fatty methyl ester sulfonate, J. Surf. Deterg. 11 (2008) 181-186.

[3] L. Cohen, D.W. Roberts, C. Pratesi, $\Phi$-Sulfo fatty methyl ester sulfonates (Ф-MES): a new anionic surfactant, in: E.T. Hagen (Ed.), Detergents: Types, Components and Uses, Nova Science Publishers, New York, 2011, pp. 121-142.

[4] S. Itsadanont, J.F. Scamehorn, S. Soontravanich, D.A. Sabatini, S. Chavadej, Dissolution of soap scum by surfactant. Part I: Effects of chelant and type of soap scum, J. Surfact. Deterg. 17 (2014) 849-857.

[5] S. Itsadanont, P. Theptat, J.F. Scamehorn, S. Soontravanich, D.A. Sabatini, S. Chavadej, Dissolution of soap scum by surfactants. Part III. Effect of chelant type on equilibrium solubility and dissolution rate of calcium and magnesium soap scums in various surfactant systems, J. Surfact. Deterg. 18 (2015) 925-932.

[6] P. Siwayanan, R. Aziz, N.A. Bakar, H. Ya, R. Jokiman, S. Chelliapan, Characterization of phosphate-free detergent powders incorporated with palm C16 methyl ester sulfonate (C16MES) and linear alkyl benzene sulfonic acid (LABSA), J. Surf. Deterg. 17 (2014) 871-880.

[7] P. Siwayanan, R. Aziz, N.A. Bakar, H. Ya, R. Jokiman, S. Chelliapan, Detergency stability and particle characterization of phosphate-free spray dried detergent powders 
incorporated with palm C16 methyl ester sulfonate (C16MES), J. Oleo Sci. 63 (2014) 585-592.

[8] M. Luo, Z. Jia, H. Sun, L. Liao, Q. Wen, Rheological behavior and microstructure of an anionic surfactant micelle solution with pyroelectric nanoparticle, Colloids Surf. A 395 (2012) 267-275.

[9] R. Ghazali, S. Ahmad, Biodegradability and ecotoxicity of palm stearin-based methyl ester sulphonates, J. Oil Palm Research 16 (2004) 39-44.

[10] S.E. Anachkov, S. Tcholakova, D.T. Dimitrova, N.D. Denkov, N. Subrahmaniam, P. Bhunia, Adsorption of linear alkyl benzene sulfonates on oil-water interface: Effects of $\mathrm{Na}^{+}, \mathrm{Mg}^{2+}$ and $\mathrm{Ca}^{2+}$ ions, Colloids Surf. A 466 (2015) 18-27.

[11] K.L. Matheson, M.F. Cox, D.L. Smith, Interactions between linear alkylbenzene sulfonates and water hardness ions. I. Effect of calcium ion on surfactant solubility and implications for detergency performance, Journal of the American Oil Chemists' Society 62 (1985) 1391-1396.

[12] T. Satsuki, Y. Nagoh, H. Yoshimura, Effect of calcium ions on detergency. Part 2: Interactions between a surfactant, a calcium-sequestering builder and calcium ions, Tenside Surfactants Deterg. 35 (1998) 112-118.

[13] K.D. Danov, R.D. Stanimirova, P.A. Kralchevsky, E.S. Basheva, V.I. Ivanova, J.T. Petkov, Sulfonated methyl esters of fatty acids in aqueous solutions: interfacial and micellar properties, J. Colloid Interface Sci. 457 (2015) 307-318.

[14] J.-G. Ma, B.J. Boyd, C.J. Drummond, Positional isomers of linear sodium dodecyl benzene sulfonate: solubility, self-assembly, and air/water interfacial activity, Langmuir 22 (2006) 8646-8654.

[15] V.V. Kalinin, C.J. Radke, An ion-binding model for ionic surfactant adsorption at aqueous-fluid interfaces, Colloids Surf. A 114 (1996) 337-350.

[16] P. Warszynski, W. Barzyk, K. Lunkenheimer, H. Fruhner, Surface tension and surface potential of Na $n$-dodecyl sulfate at the air-solution interface: model and experiment, J. Phys. Chem. B 102 (1998) 10948-10957.

[17] P.A. Kralchevsky, K.D. Danov, G. Broze, A. Mehreteab, Thermodynamics of ionic surfactant adsorption with account for the counterion binding: effect of salts of various valency, Langmuir 15 (1999) 2351-2365.

[18] D.S. Valkovska, G.C. Shearman, C.D. Bain, R.C. Darton, J. Eastoe, Adsorption of ionic surfactants at an expanding air-water interface, Langmuir 20 (2004) 4436-4445.

[19] V.B. Fainerman, D. Möbius, R. Miller, Surfactants: Chemistry, Interfacial Properties, Applications, Elsevier, Amsterdam, 2001.

[20] P.A. Kralchevsky, K.D. Danov, V.L. Kolev, G. Broze, A. Mehreteab, Effect of nonionic admixtures on the adsorption of ionic surfactants at fluid interfaces. 1. Sodium dodecyl sulfate and dodecanol, Langmuir 19 (2003) 5004-5018. 
[21] K.D. Danov, S.D. Kralchevska, P.A. Kralchevsky, G. Broze, A. Mehreteab, Effect of nonionic admixtures on the adsorption of ionic surfactants at fluid interfaces. 2. Sodium dodecylbenzene sulfonate and dodecylbenzene, Langmuir 19 (2003) 5019-5030.

[22] P.A. Kralchevsky, K.D. Danov, Chemical physics of colloid systems and interfaces, in: K.S. Birdi (Ed.) Handbook of Surface and Colloid Chemistry, $4^{\text {th }}$ ed., CRC Press, Boca Raton, 2015, pp. 247-412 (Chapter 4). DOI: 10.1201/b18633-5

[23] T.D. Gurkov, P.A. Kralchevsky, K. Nagayama, Formation of dimers in lipid monolayers, Colloid Polym. Sci. 274 (1996) 227-238.

[24] R.A. Robinson, R.H. Stokes, Electrolyte Solutions, Butterworth, London, 1959.

[25] K.D. Danov, P.A. Kralchevsky, K.P. Ananthapadmanabhan, A. Lips, Interpretation of surface-tension isotherms of n-alkanoic (fatty) acids by means of the van der Waals model, J. Colloid Interface Sci. 300 (2006) 809-813.

[26] T.L. Hill, An Introduction to Statistical Thermodynamics, Dover Publications, New York, 1987.

[27] V.L. Kolev, K.D. Danov, P.A. Kralchevsky, G. Broze, A. Mehreteab, Comparison of the van der Waals and Frumkin adsorption isotherms for sodium dodecyl sulfate at various salt concentrations, Langmuir 18 (2002) 9106-9109.

[28] N. Vlachy, B. Jagoda-Cwiklik, R. Vácha, D. Touraud, P. Jungwirth, W. Kunz, Hofmeister series and specific interactions of charged headgroups with aqueous ions, Adv. Colloid Interface Sci. 146 (2009) 42-47.

[29] D. Vollhardt, G. Emrich, Coadsorption of sodium dodecyl sulfate and medium-chain alcohols at the air-water interface, Colloids Surf. A 161 (2000) 173-182.

[30] M. Bourrel, R.S. Schechter, Microemulsions and Related Systems, M. Dekker, New York, 1988, p. 87.

[31] S.S. Tzocheva, P.A. Kralchevsky, K.D. Danov, G.S. Georgieva, A.J. Post, K.P. Ananthapadmanabhan, Solubility limits and phase diagrams for fatty acids in anionic (SLES) and zwitterionic (CAPB) micellar surfactant solutions, J. Colloid Interface Sci. 369 (2012) 274-286.

[32] P.C. Schulz, J.L. Rodriguez, R.M. Minardi, M.B. Sierra, M.A. Morini, Are the mixtures of homologous surfactants ideal?, J. Colloid Interface Sci. 303 (2006) 264-271.

[33] K.D. Danov, P.A. Kralchevsky, K.P. Ananthapadmanabhan. Micelle-monomer equilibria in solutions of ionic surfactants and in ionic-nonionic mixtures: A generalized phase separation model, Adv. Colloid Interface Sci. 206 (2014) 17-45.

[34] S.S. Tzocheva, K.D. Danov, P.A. Kralchevsky, G.S. Georgieva, A.J. Post, K.P. Ananthapadmanabhan. Solubility limits and phase diagrams for fatty alcohols in anionic (SLES) and zwitterionic (CAPB) micellar surfactant solutions, J. Colloid Interface Sci. 449 (2015) 46-61. 


\title{
Supplementary Material
}

for the article

\section{Sulfonated methyl esters, linear alkylbenzene sulfonates and their mixed solutions: micellization and effect of $\mathrm{Ca}^{2+}$ ions}

\author{
Veronika I. Ivanova ${ }^{\text {, }}$ Rumyana D. Stanimirova ${ }^{\text {a }}$, Krassimir D. Danov ${ }^{\text {, }}$, \\ Peter A. Kralchevsky ${ }^{\mathrm{a},{ }^{*},}$, Jordan T. Petkov ${ }^{\mathrm{b}}$
}

${ }^{a}$ Department of Chemical \& Pharmaceutical Engineering, Faculty of Chemistry \& Pharmacy. Sofia University, 1164 Sofia, Bulgaria. E-mail: pk@lcpe.uni-sofia.bg; Fax: +35929625643

${ }^{\mathrm{b}}$ KL-Kepong Oleomas SDN BHD, Menara KLK, Jalan PJU 7/6, Mutiara Damansara, 47810 Petaling Jaya, Selangor Dalur Ehsan, Malaysia

\section{Appendix A. Additional experimental results and theoretical predictions}

Fig. A1 shows theoretical curves for the adsorption of the nonionic admixture (unsulfonated surfactant molecules), $\Gamma_{\mathrm{n}}$, vs. the surfactant concentration calculated using the parameter values in Table 1 in the main text of the article. $\Gamma_{\mathrm{n}}$, is the greatest for C14-SME for two main reasons: (i) the fraction of the nonionic admixture, $x_{n}$, is greater for C14-SME as compared to C16-SME (see the main text), and (ii) the shorter chain (the smaller adsorption constant $K_{1}$ ) for C14-SME makes the contribution of the electrostatic energy more significant as compared to the hydrophobic energy related to the surfactant-tail adsorption.

Despite the greatest fraction of the nonionic admixture, $x_{\mathrm{n}}$, in LAS, the respective values of $\Gamma_{\mathrm{n}}$ are smaller than those for C14-SME (compare Figs. A1a and c) because of the greater values of $K_{1}$ and $\hat{\beta}_{11}$ for LAS (see Table 1 in the main text), which make relatively smaller the contribution of electrostatic energy upon adsorption of LAS as compared to C14SME.

Figs. A2 and A3 show plots of the electric conductivity of mixed solutions of SME and CAPB (cocamidopropyl betaine) vs. the total surfactant concentration. From the kinks in these plots, the values of CMC shown in Fig. 8b of the main text have been determined. 
(a)

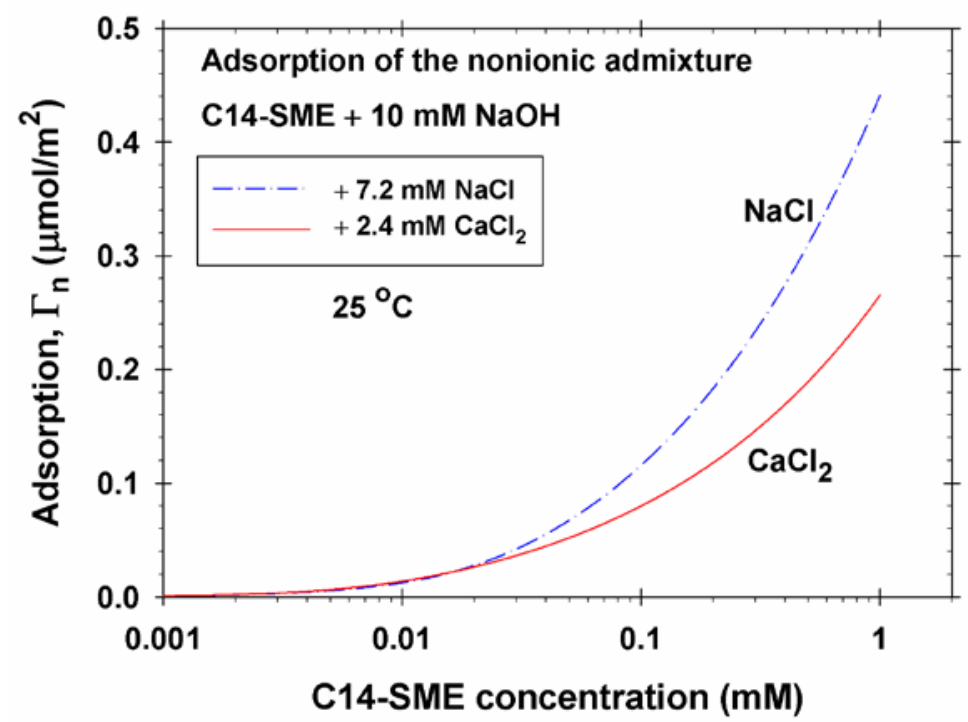

(b)

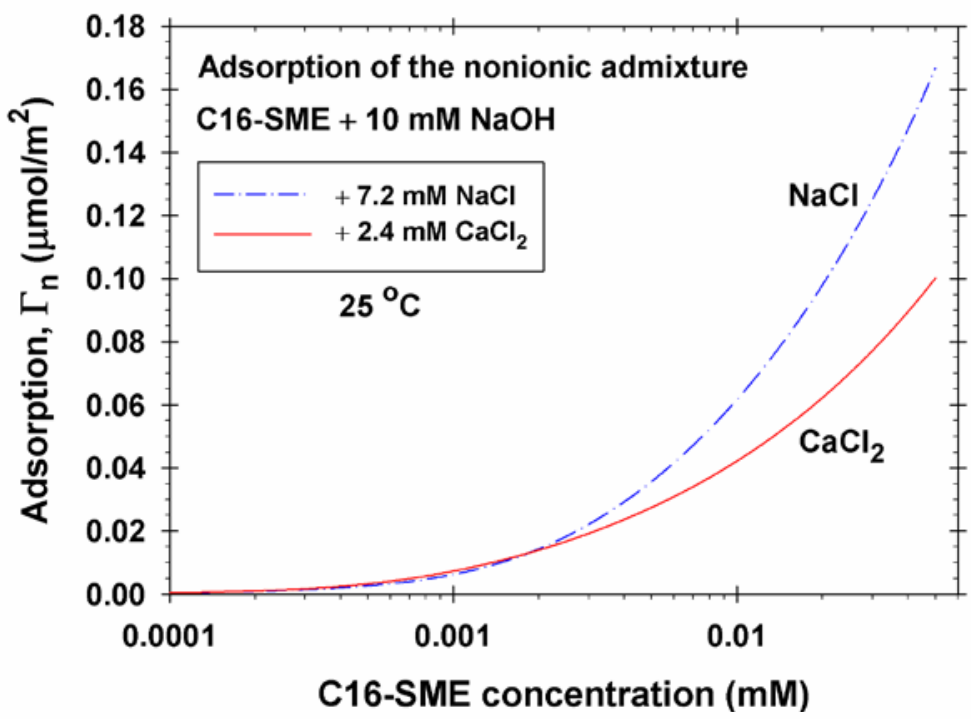

(c)

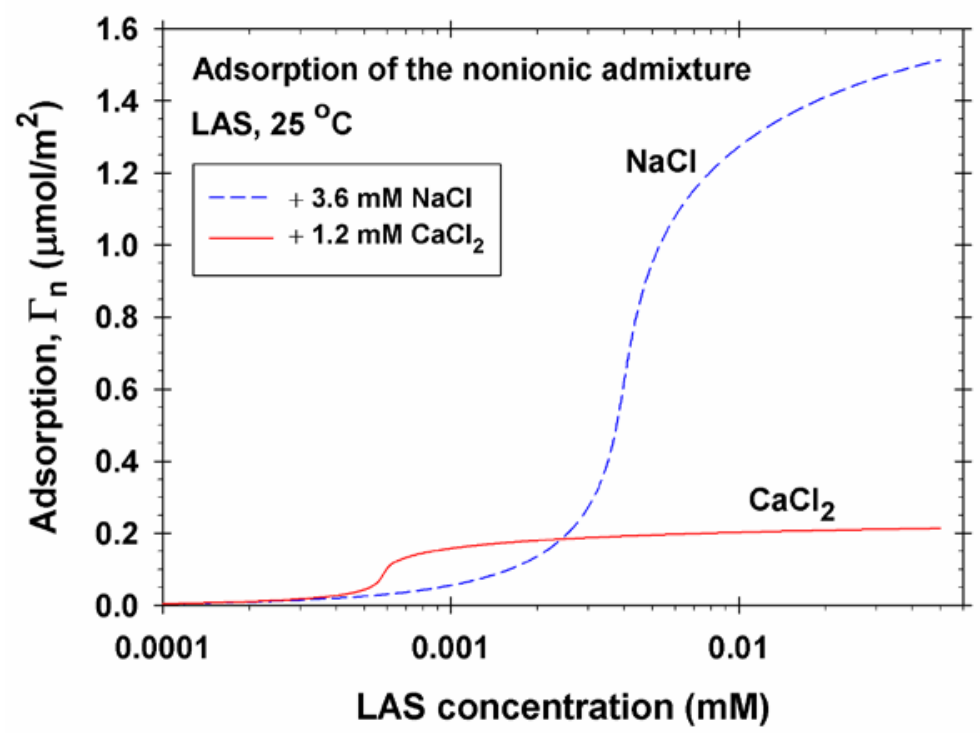

Fig. A1. Plot of the adsorption of the nonionic admixture (unsulfonated surfactant molecules), $\Gamma_{\mathrm{n}}$, vs. the surfactant concentration for (a) C14-SME; (b) C16-SME, and (c) LAS: Theoretical curves calculated using the parameter values in Table 1 determined from the fits of experimental data in Figs. 2a,b,c in the main text of the article. 
(a)

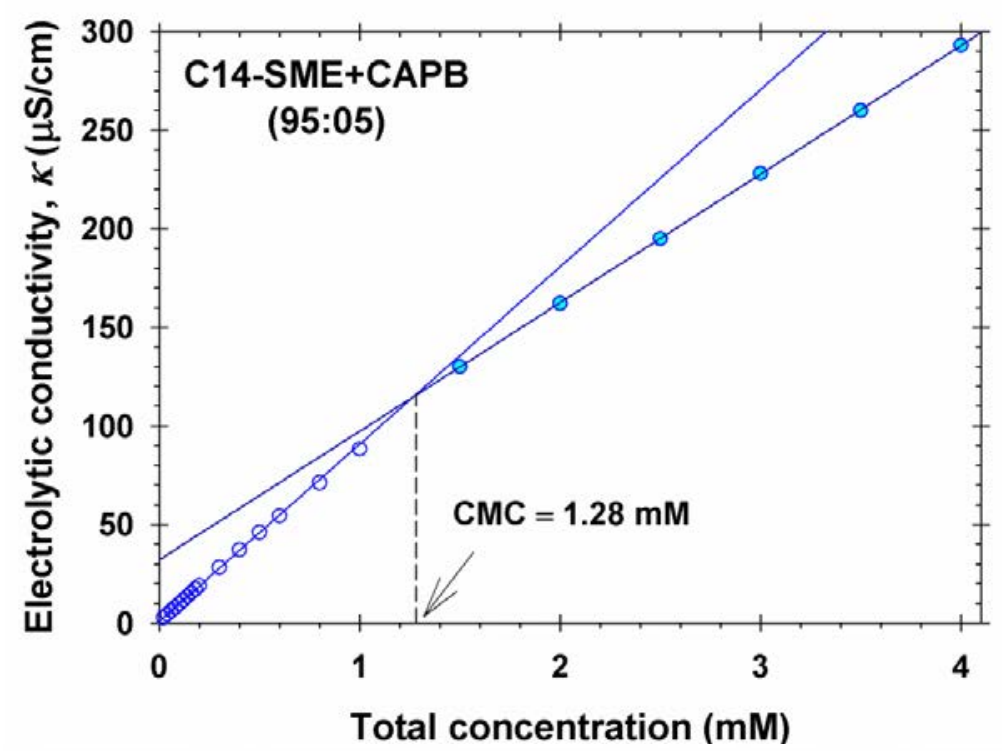

(b)

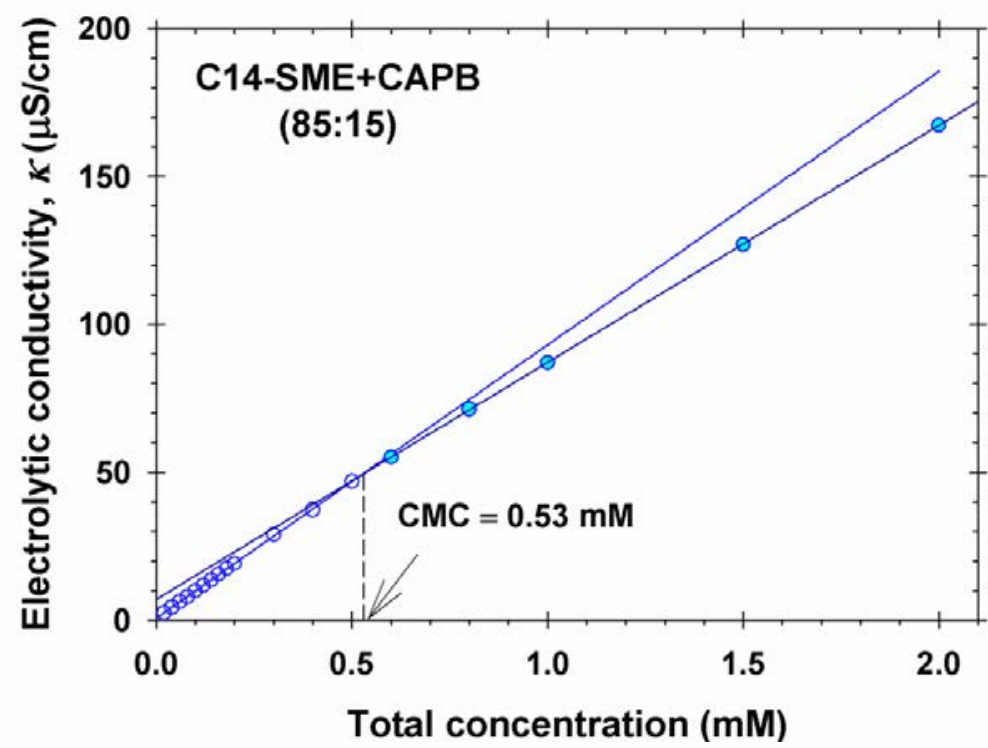

(c)

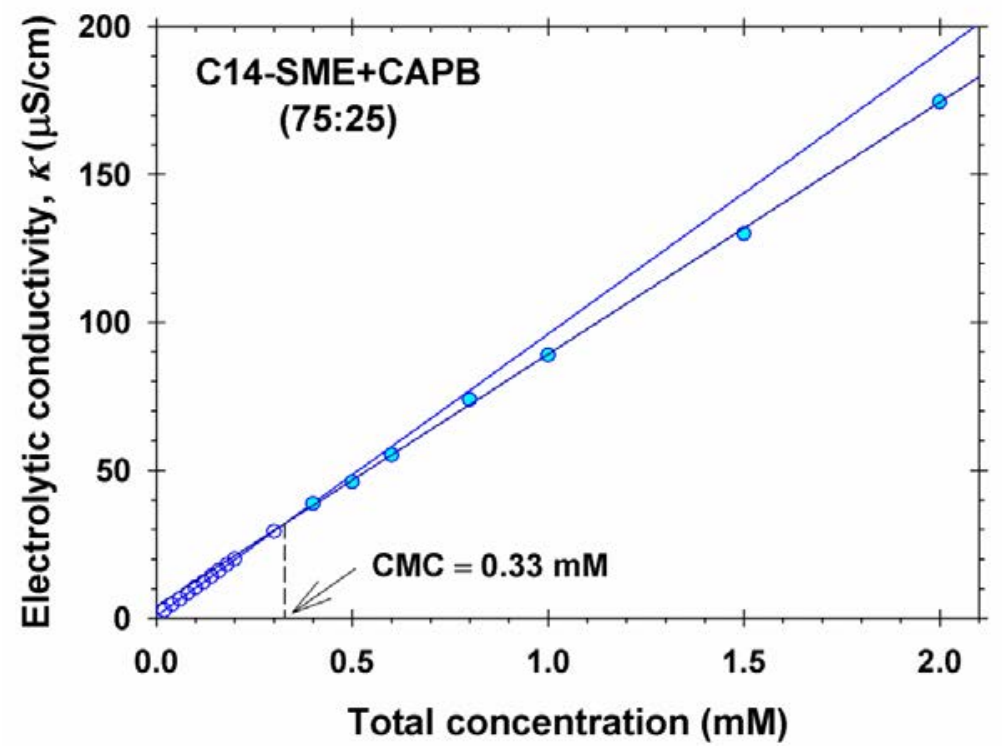

Fig. A2. Determination of the CMC of mixed solutions of C14-SME and CAPB by conductivity measurements. Plots of the solution's electric conductivity vs. the total surfactant concentration at different molar ratios of C14-SME to CAPB: (a) 95:05; (b) 85:15, and (c) $75: 25$. 
(a)

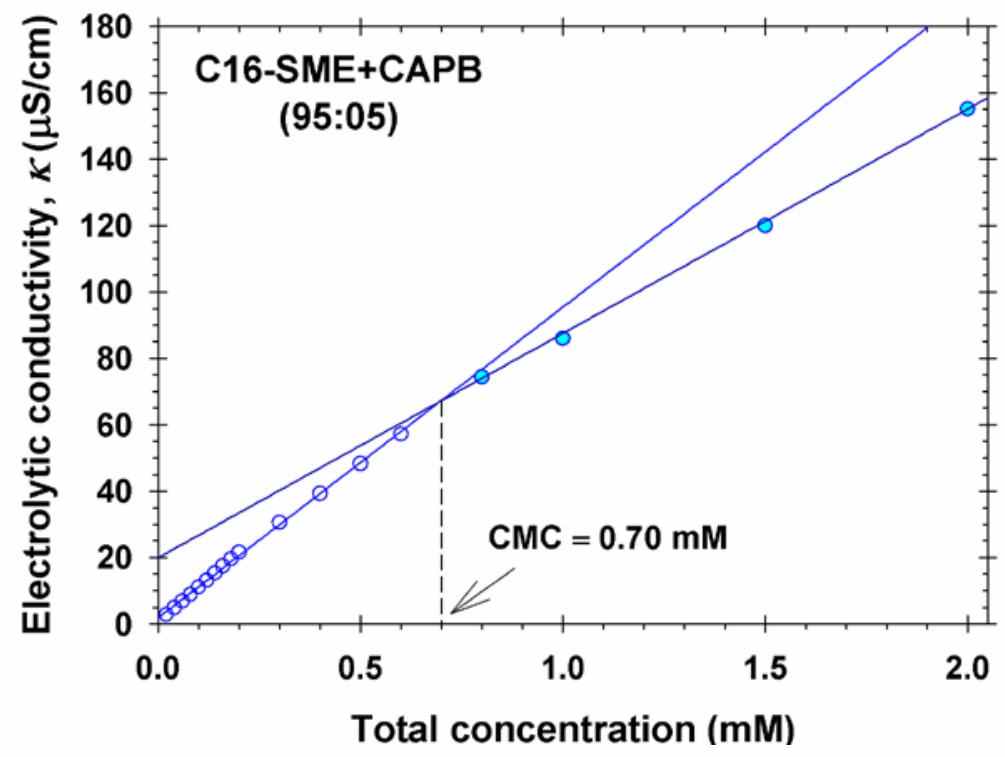

(b)

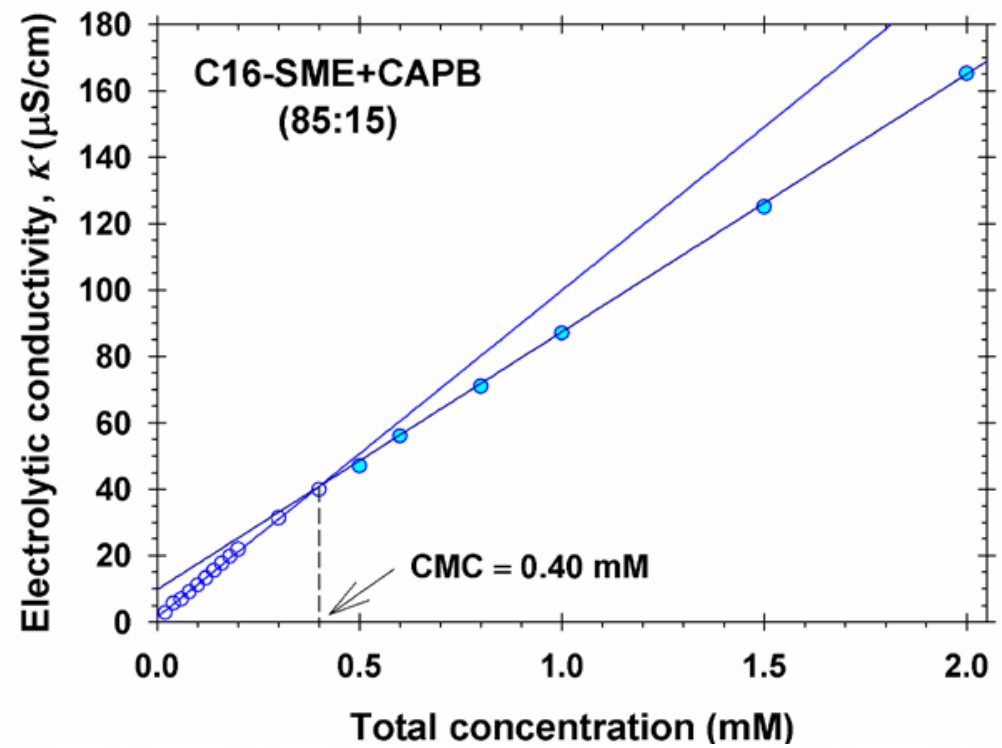

(c)

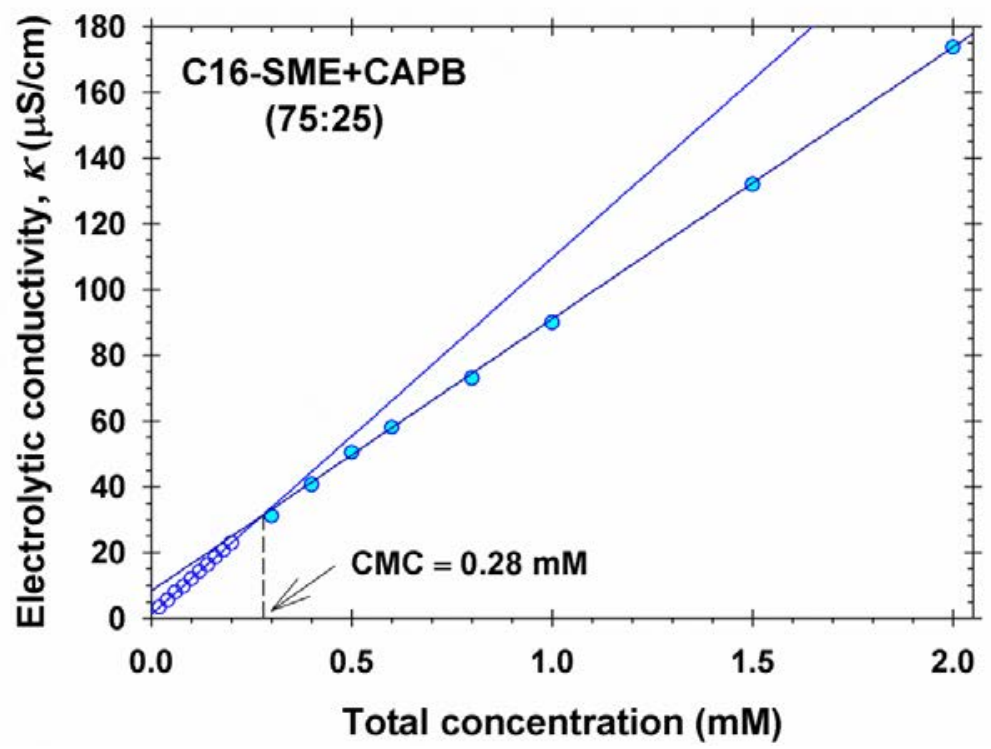

Fig. A3. Determination of the CMC of mixed solutions of C16-SME and CAPB by conductivity measurements. Plots of the solution's electric conductivity vs. the total surfactant concentration at different molar ratios of C16-SME to CAPB: (a) 95:05; (b) 85:15, and (c) $75: 25$. 